HANNAH BROWN

\title{
INCIDENTAL FINDINGS IN HUMAN SUBJECTS RESEARCH: IS IGNORANCE REALLY BLISS?
}

\author{
LLM RESEARCH PAPER \\ LAWS 513: LAW AND MEDICINE
}

FACULTY OF LAW

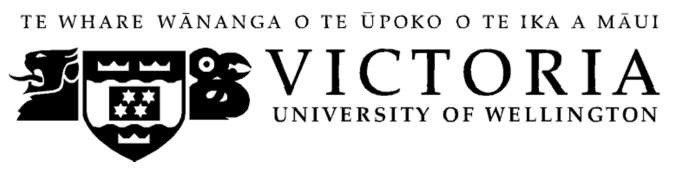

2013 


\begin{abstract}
Human subjects research has the potential to produce information beyond the aims of the research study. This information may, nevertheless, have health or reproductive significance for the research participant. With the development of sophisticated technologies, these occurrences, known as incidental findings (IFs), are becoming increasingly common. As yet, however, there is no consensus on how IFs in human subjects research should be managed. This paper examines the current law and guidelines relating to human subjects research, and in doing so determines that research participants are inadequately informed about IFs. Consequently, their ability to make an informed choice about and provide informed consent to research procedures is compromised. After addressing the ethical and practical issues most salient to IFs, a framework for their management is developed. The framework sets out the information that should be discussed with research participants during the informed consent process. Recommendations for how this framework should be implemented are then made. The paper concludes that guidelines establishing minimum standards for communicating the possibility and presence of IFs are urgently required so that the rights of research participants are sufficiently protected.
\end{abstract}

\title{
Word length
}

The text of this paper (excluding abstract, table of contents, footnotes and bibliography) comprises approximately 15,007 words. 


\section{Table of Contents}

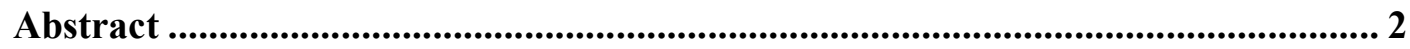

Word length .....................................................................................................................................

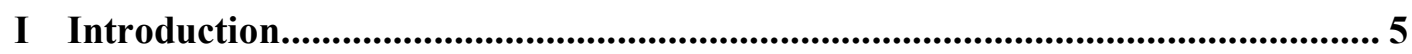

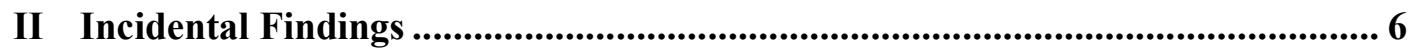

III The Current Situation .................................................................................... 8

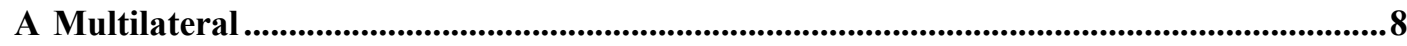

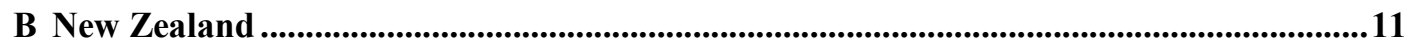

1 Code of Health and Disability Services Consumers' Rights ............................................... 11

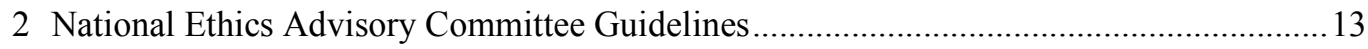

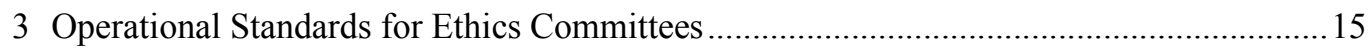

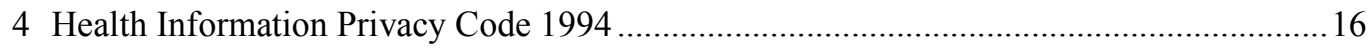

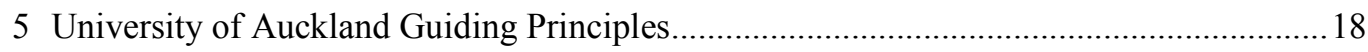

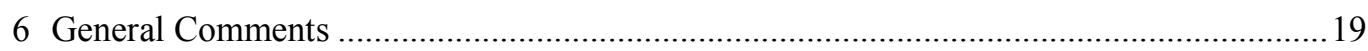

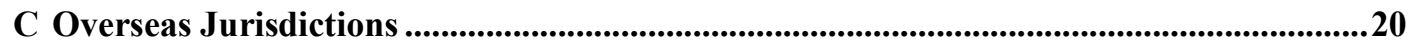

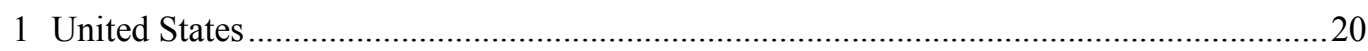

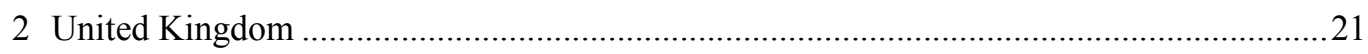

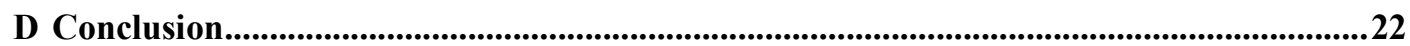

IV Towards a Comprehensive Approach - Important Considerations ................ 22

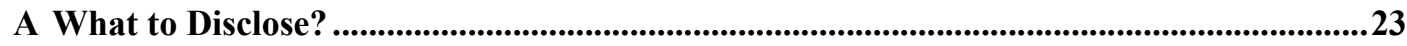

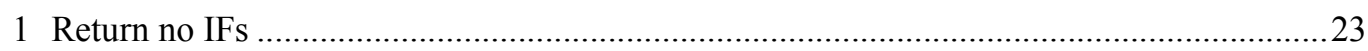

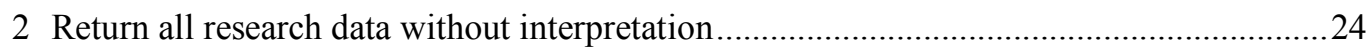

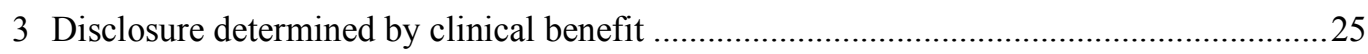

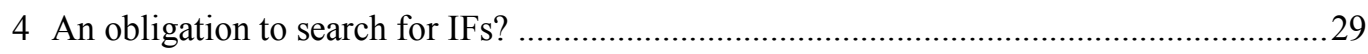

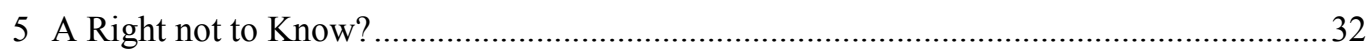

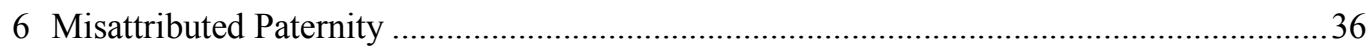

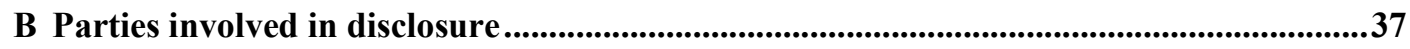

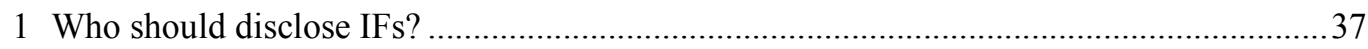

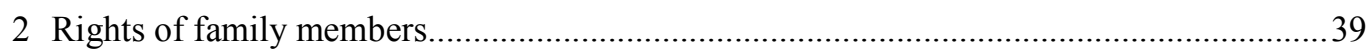

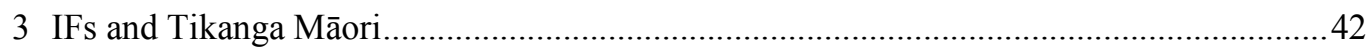

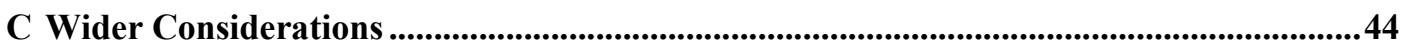

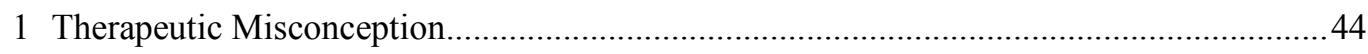

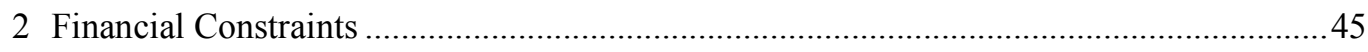

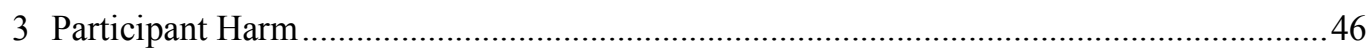

V How should Incidental Findings be managed in New Zealand? ...................... 47

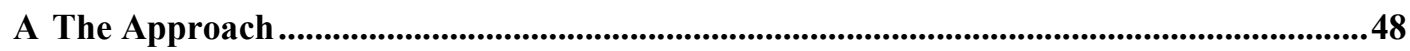

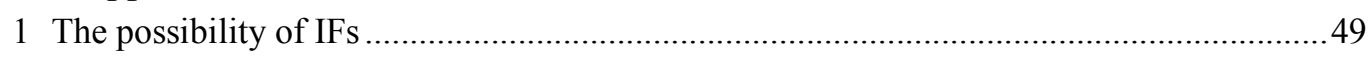

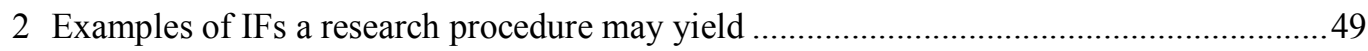

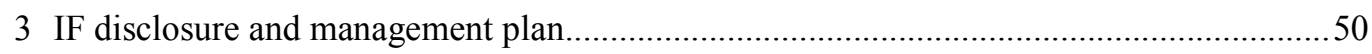

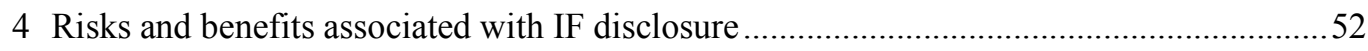

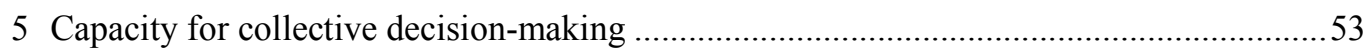


B Implementing the Approach ................................................................................53

1 National Ethics Advisory Committee Guidelines........................................................5

2 Code of Health and Disability Services Consumers' Rights ..........................................54

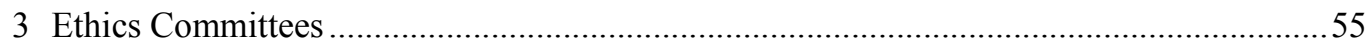

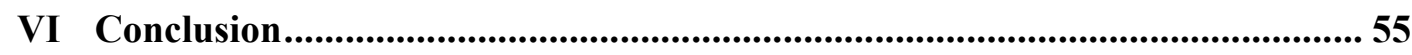

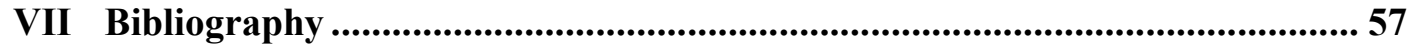




\section{Introduction}

At first glance, the problem of incidental findings (IFs) may seem incidental. For so long, our attention has been devoted to the development of human subjects research. ${ }^{1}$ It may, therefore, be assumed that research teams know how to address any clinically relevant information generated unexpectedly from such research. ${ }^{2}$ The truth, however, is that IFs are far from inconsequential and, as yet, there is no consensus as to their management in human subjects research. ${ }^{3}$ Although IFs are not a new phenomenon, the development of sophisticated technologies used to generate images, scans, and data means that the likelihood of such discoveries has increased dramatically. ${ }^{4}$ In light of this, it is more important than ever to develop a coherent framework for the management of IFs in research.

The focus of this paper is on IFs discovered in the course of research, and not clinical care. A significant literature already exists addressing IFs in clinical care. Attention to IFs in research, on the other hand, is at an earlier stage and is comparatively more contentious. $^{5}$

This paper starts with an overview of the issue of IFs and the context in which they arise. Part III examines the current framework for addressing IFs in human subjects research both in New Zealand and internationally. Part IV addresses both the ethical and practical issues salient to IFs, before Part V, in consideration of these issues, puts forward a proposal for the management of IFs in New Zealand. This final part also examines the ways in which this proposal should be implemented. The paper concludes that guidelines establishing minimum standards for communicating the possibility and presence of IFs in research are required. How such regulations should look is, nonetheless, the subject of an intense debate and, at present, is highly controversial. ${ }^{6}$

\footnotetext{
1 Susan M Wolf "Introduction: The Challenge of Incidental Findings" (2008) 36 J L M \& E 216 at 216.

$2 \quad$ At 216. 


\section{Incidental Findings}

An IF may be defined as "a finding that has potential health or reproductive significance, unknown to the participant, which is discovered in the course of conducting research, but is unrelated to the purpose and beyond the aims of the study". ${ }^{7}$ Examples of common IFs include one on a genomic microarray suggesting a genetic variant of potential clinical importance beyond the variants directly under study, an IF of misattributed paternity in a genetic family study, an unexpected mass or aneurysm identified in the course of an magnetic resonance imaging (MRI) scan of the brain, and an unexpected mass at the base of the lung discovered in a CT colonoscopy. ${ }^{8}$

As research becomes increasingly large-scale, using powerful technologies, the problem of incidental findings is becoming more serious. ${ }^{9}$ Although virtually any study involving a human subject could reveal an IF, in recent years, researchers in imaging and genetics, in particular, have turned their attention to this issue. ${ }^{10}$ In the past, most genetics studies examined a limited number of genes or sites of genetic variation. ${ }^{11}$ The researcher would focus on a few candidate genes that were thought to affect the trait or disease of interest. $^{12}$ The scope of inquiry was narrow and hence the likelihood of IFs was relatively low. ${ }^{13}$ However as a result of technological advances, making it possible to examine the human brain and the human genome in far greater detail than ever before, these research areas are expanding rapidly. ${ }^{14}$ With that expansion comes an increased likelihood that incidental findings will be detected. ${ }^{15}$ To illustrate, a 2010 meta-analysis of 16 studies involving 19,559 participants found that the prevalence of incidental findings on brain MRI was 2.7 per cent. ${ }^{16}$ With body MRI, the prevalence is 12.8 per

(2011) 8 J Bioeth Inq 59 at 59.

$7 \quad$ Lisa S Parker “The Future of Incidental Findings: Should they be Viewed as Benefits?” (2008) 36

J L M \& E 341 at 342.

Wolf and others, above $\mathrm{n} 5$, at 219.

Wolf, above n 1, at 217.

Karen Ross "When Volunteers Are Not Healthy" (2005) 6 EMBO Rep 1116 at 1116.

Wright Clayton, above n 2, at 287.

At 287.

At 287.

Ross, above n 12, at 1116.

At 1116.

T C Booth and others "Incidental findings found in "healthy" volunteers during imaging performed for research: current legal and ethical implications" (2010) 83 Brit J Radiol 456 at 456. 
cent and with CT colonoscopy, extra-colonic IFs require further investigation or medical intervention in 5 to 8 per cent of cases. ${ }^{17}$ Finally, family genetic studies reveal misattributed parentage at an estimated incidence of 10 per cent. ${ }^{18}$

This paper focuses on IFs in two major research domains, genetic research and imaging research. Both empirical studies of IFs and normative discussion on how best to handle IFs are more advanced in imaging than in genetic research. ${ }^{19}$ This paper offers recommendations for how to anticipate and manage IFs in both research domains. What distinguishes the issue of IFs in genetic research from IFs in imaging and other research procedures is the likelihood and scope of potential IFs. ${ }^{20}$ In imaging research, the question is whether one of a limited number of IFs will occur. ${ }^{21}$ In the context of genetic research however, the question is how to deal with the hundreds of different IFs that can potentially be uncovered in any individual research participant's genetic material. ${ }^{22}$ Nevertheless, the analysis and recommendations presented in this paper are likely to have broader application to other domains of human subjects research. ${ }^{23}$

The focus of this paper is on physiological and genetic IFs, rather than social or behavioural IFs. An example of the latter would be signs of alcohol abuse in an adolescent participating in an MRI study of adolescent cognition that is unrelated to alcohol use. ${ }^{24}$ Other examples include signs of physical abuse or suicidality in studies unrelated to those phenomena. ${ }^{25}$ Social and behavioural IFs raise somewhat different issues and are therefore not the focus of this paper.

IFs can be clinically significant for a number of reasons. For example, an IF can indicate an urgent, clinically actionable condition such as a predisposition to non-polyp forming

\footnotetext{
$17 \quad$ At 456 .

18 Wolf, above n 1 , at 216.

19 Wolf and others, above $\mathrm{n} 5$, at 220.

$20 \quad$ Elizabeth R Pike, Karen Rothenberg and Benjamin E Berkman "Finding Fault? Exploring Legal Duties to Return Incidental Findings in Genomic Research" (Legal Studies Research Paper, University of Maryland, 2013) at 4.

$21 \quad$ At 4.

$22 \quad$ At 4.

23 Wolf and others, above n 5, at 220.

24 At 220.

25 Wolf and others, above n 5, at 220.
} 
cancer, a cancer that is fatal and otherwise undetectable through standard screening. ${ }^{26}$ An IF could predict a propensity to develop disease in the future, such as breast cancer or Alzheimer's. ${ }^{27}$ Some IFs will reveal information that is not clinically significant, but may nevertheless have wide-reaching implications. An example of this is a finding of misattributed paternity. Yet other IFs, perhaps even most IFs, may instead be something the meaning and importance of which is unknown. ${ }^{28}$ When the consequence of the finding has clinical significance, research participants may benefit from learning about IFs discovered during the course of research. A research participant who learns that she has a BRCA mutation, an indication of a predisposition to developing breast cancer, for example, could take measures aimed at preventing undesirable future medical outcomes, including participation in regular mammogram screening. ${ }^{29}$

IFs can occur in a variety of settings. They may indicate important clinically actionable results, or may instead be findings the meaning and importance of which are unknown. What is known, however, is that as technology develops, the frequency with which IFs are being uncovered is increasing. For this reason, it is important to develop a framework for their effective management.

\section{The Current Situation}

The current framework relating to IFs is marked by a lack of clarity and an absence of consensus. ${ }^{30}$ Laws and regulations offer little guidance on how IFs should be managed. ${ }^{31}$ The following section examines current international and domestic IF guidelines, and in doing so, illustrates the lack of coordination in this area.

\section{A Multilateral}

Since the late 19th century, biomedical research involving humans has been the subject of intense international ethical and legal debate. ${ }^{32}$ This has led to a number of regulatory

26 Pike, Rothenberg and Berkman, above $\mathrm{n} 20$, at 3.

$27 \quad$ At 3.

28 At 3.

$29 \quad$ At 3.

$30 \quad$ Susan M Wolf, Jordan Paradise and Charlisse Caga-anan "The Law of Incidental Findings in Human Subjects Research: Establishing Researcher's Duties” (2008) 36 J L M \& E 361 at 362.

At 362.

Heinrichs, above n 6, at 59. 
frameworks, the most prominent being the Nuremberg Code, the Declaration of Helsinki, the Council of Europe's Additional Protocol to the Convention on Human Rights and Biomedicine, concerning Biomedical Research and the Council for International Organizations of Medical Sciences (CIOMS) International Ethical Guidelines for Biomedical Research Involving Human Subjects. ${ }^{33}$

The Nuremberg Code is a set of ethical principles for human experimentation created following the Nuremberg Trials at the end of World War Two. The Nuremberg Code emphasises the importance of voluntary consent. Article 1 provides that: ${ }^{34}$

...before the acceptance of an affirmative decision by the experimental subject there should be made known to him... all inconveniences and hazards reasonable to be expected; and the effects upon his health or person which may possibly come from his participation in the experiment. The duty and responsibility for ascertaining the quality of the consent rests upon each individual who initiates, directs or engages in the experiment.

Similarly, the Declaration of Helsinki (the Declaration) is a set of ethical principles developed for the medical community by the World Medical Association (WMA). Article 24 of the Declaration provides: ${ }^{35}$

In medical research involving competent human subjects, each potential subject must be adequately informed of... any anticipated benefits and potential risks of the study and the discomfort it may entail, and any other relevant aspects of the study... After ensuring that the potential subject has understood the information, the physician or another appropriately qualified individual must then seek the potential subject's freely given informed consent, preferably in writing.

The Declaration has been described as "the most widely accepted guidance worldwide on medical research involving human subjects. ${ }^{, 36}$ Though it is not a legally binding instrument at international law, along with the Nuremberg Code, the Declaration draws its authority from the degree to which it has been codified in, or influenced, national or

\footnotetext{
$33 \quad$ At 59 .

$34 \quad$ Nuremberg Code (1947), art 1.

35 Declaration of Helsinki: Ethical Principles for Medical Research Involving Human Subjects (adopted by the 18th WMA General Assembly, June 1964), art 24.

36 B Christie "Doctors revise Declaration of Helsinki" (2000) 321 BMJ 913 at 913.
} 
regional legislation and regulations. ${ }^{37}$ In New Zealand, guidelines for health research released by the National Ethics Advisory Committee purport to accord with these key international instruments. ${ }^{38}$

The Council of Europe's Additional Protocol to the Convention on Human Rights and Biomedicine, concerning Biomedical Research (Additional Protocol to the Convention) provides: ${ }^{39}$

If research gives rise to information of relevance to the current or future health or quality of life of research participants, this information must be offered to them. That shall be done within a framework of health care or counselling. In communication of such information, due care must be taken in order to protect confidentiality and to respect any wish of a participant not to receive such information.

This provision emphasises the importance of notifying participants of "relevant" IFs. Nevertheless, it leaves unclear how investigators should determine what IF is "relevant" for each research participant. ${ }^{40}$ Moreover, the Additional Protocol to the Convention only applies to European Union states, and therefore excludes New Zealand.

Finally, the CIOMS International Ethical Guidelines for Biomedical Research Involving Human Subjects recommends that individual participants be informed of "any finding that relates to their particular health status". ${ }^{41}$

Despite not expressly referring to IFs, these key international instruments nevertheless emphasise the necessity of, firstly, informing a participant of any anticipated benefits and risks of a study, and secondly, offering information relevant to a participant's health

37 E Deutsch and J Taupitz "Freedom of control and biomedical research" (1999) 150 Bull Med Ethics 22 at 22. National Ethics Advisory Committee Ethical Guidelines for Intervention Studies: Revised edition (2012) at 1.7; National Ethics Advisory Committee Ethical Guidelines for Observational Studies: Observational research, audits and related activities (2012) at 1.6. Biomedical Research 2005 ETS 195 (opened for signature January 25 2005, entered into force September 1 2007), art 27.

$40 \quad$ Booth and others, above n 16, at 460.

41 Council for International Organizations of Medical Sciences in collaboration with the World Health Organization International ethical guidelines for biomedical research involving human subjects (2002) at 38 . 
or quality of life arising out of a study. The author submits that these provisions are sufficiently wide to include risk or presence of many IFs. Where an IF is a reasonably expected risk of a study, or if research gives rise to an IF of relevance to the current or future health or quality of life of a participant, according to the international framework, this information should be disclosed to the participant.

The international framework detailed above has influenced legislative and regulatory systems worldwide. Many countries have enacted laws detailing the rights of research participants, and regulating at least some forms of human biomedical research.

\section{B New Zealand}

Human subjects research in New Zealand is comprehensively regulated. The current framework, however, is disjointed and lacks guidance on how IFs should be managed.

\section{Code of Health and Disability Services Consumers' Rights}

The rights of health consumers and responsibilities of health care providers in relation to research are detailed in the Health and Disability Commissioner (Code of Health and Disability Services Consumers' Rights) Regulations 1996 (the Code of Rights). The Code of Rights is established as a regulation under the Health and Disability Commissioner Act 1994, and sets out the rights of all health and disability services consumers, including those involved in teaching and research.

The Code of Rights stipulates that every consumer has the right, and researchers a corresponding duty, to have services provided that comply with legal, professional, ethical and other relevant standards. ${ }^{42}$ Furthermore the Code of Rights provides that every consumer has the right to have services provided in a manner that minimises potential harm to, and optimises the quality of life of, that consumer. ${ }^{43}$

\footnotetext{
$42 \quad$ Health and Disability Commissioner (Code of Health and Disability Services Consumers' Rights) Regulations 1996, sch, cl 2, right 4(2) (Code of Rights).

43 Schedule, cl 2, right 4(4).
} 
The Code of Rights is based upon the central right of health care consumers to be fully informed in order to make an informed choice about the health and disability services they receive. ${ }^{44}$ The right to be fully informed is explicated in right 6 , which provides: ${ }^{45}$

(1) Every consumer has the right to information that a reasonable consumer, in that consumer's circumstances would expect to receive, including -

(b) An explanation of the options available, including an assessment of the expected risks, side effects, benefits and costs of each option; and

(d) Notification of any proposed participation in teaching or research, including whether the research requires and has received ethical approval; and

(f) The results of tests; and

(g) The results of procedures.

(2) Before making a choice or giving consent, every consumer has the right to the information that a reasonable consumer, in that consumer's circumstances, needs to make an informed choice or give informed consent.

Right 9 provides that the rights contained in the Code of Rights extend to those occasions when a consumer is participating in, or it is proposed that a consumer participate in research. ${ }^{46}$ Where the consumer is to participate in any research, informed consent must be in writing. ${ }^{47}$

The focus of the Code of Rights is on the consumer and the information the consumer needs to be fully informed, not on whether the conduct of the provider is seen as

$44 \quad$ Katharine Greig 'Informed Consent in the Code of Health and Disability Services Consumers' Rights" (8 February 2000) <http://www.hdc.org.nz/education/presentations/informed-consent-inthe-code-of-health-and-disability-services-consumers\%27-rights $>$.

$45 \quad$ Code of Rights, sch, cl 2, right 6.

$46 \quad$ Schedule, cl 2, right 9.

$47 \quad$ Schedule, cl 2, right 7. 
reasonable in the circumstances. ${ }^{48}$ There has been little case law in New Zealand dealing with this issue, however useful guidance can be gleaned from decisions in other jurisdictions. ${ }^{49}$ The patient-focused test developed in North American and Australian Courts, and in particular, draws on the decision of the High Court of Australia (HCA) in Rogers $v$ Whitaker, which has since been applied in New Zealand. ${ }^{50}$ The HCA defined the level of detail required when informing individuals of the risks associated with a health service as: ${ }^{51}$

Enough information... so that a reasonable person in the patient's position, would, if warned of the risk, be likely to attach significance to it, or if the medical practitioner is or should be reasonably aware that the patient, if warned of the risk, would be likely to attach significance to it.

In practice, the obligations under right 6 require the provider to make judgements as to the 'expected risks' associated with the procedure and what the 'reasonable consumer in the consumer's circumstances' would want to know. As with the international framework, the Code of Rights makes no explicit reference to IFs, however the author submits that in order to be fully informed, a reasonable consumer would want to know about the risk of IFs and how they would be managed, should results disclose their presence. Consequently, under right 6 , IFs should be considered an 'expected risk'.

\section{National Ethics Advisory Committee Guidelines}

Health and Disability Ethics Committees (HDECs) are responsible for ensuring that proposed health and disability research meets established ethical standards. ${ }^{52}$ These ethical standards are set out in guidelines authored by the National Ethics Advisory Committee (NEAC). Health and disability researchers, and not HDECs, however, are responsible for ensuring that their research meets these standards at all times. This responsibility is consistent with the aforementioned duty imposed on researchers by

\footnotetext{
$48 \quad$ Greig, above n 44.

49 Committee of Inquiry into Allegations Concerning the Treatment of Cervical Cancer at National Women's Hospital and into Other Related Matters The Report of the Cervical Cancer Inquiry (Government Printing Office, July 1988) at 134.

$50 \quad$ B v Medical Council HC Auckland HC 11-96, 8 July 1996 at 17.

$51 \quad$ Rogers $v$ Whitaker (1992) 175 CLR 479 (HCA) at 490.

52 National Ethics Advisory Committee Ethical Guidelines for Observational Studies: Observational research, audits and related activities, above n 38, at Appendix 1.
} 
right 4(2) of the Code of Rights. ${ }^{53}$

The NEAC's Ethical Guidelines for Intervention Studies and Ethical Guidelines for Observational Studies (the Guidelines), aim to contribute to better health outcomes in New Zealand by assisting researchers to perform sound studies. ${ }^{54}$ The Guidelines constitute ethical standards for the purpose of right 4(2) of the Code of Rights, meaning that consumers have a right, and researchers, a corresponding duty, to provide services in accordance with the Guidelines. ${ }^{55}$

An intervention study is a study in which the researcher controls and studies an intervention provided to participants for the purpose of adding to knowledge of the health effects of that intervention. ${ }^{56}$ Many intervention studies are clinical trials. ${ }^{57}$ Similarly, the primary purpose for observational research is to add to generalisable knowledge about a health or disability issue, and may include cohort studies ${ }^{58}$ and case control studies. ${ }^{59}$ Human subjects research may take the form of either an intervention or observational study.

The Guidelines provide that information given to potential participants should outline the foreseeable risks and side effects of study participation, including any risks to the health of a participant's family members. ${ }^{60}$ Importantly, if it is reasonably foreseeable that health problems previously unknown to the individual participant could be identified during the study process, the Guidelines state that arrangements for referral,

53 Health and Disability Ethics Committee Standard Operating Procedures for Health and Disability Ethics Committees (2012) at [9].

54 National Ethics Advisory Committee Ethical Guidelines for Intervention Studies: Revised edition, above $\mathrm{n} 38$, at IV.

$55 \quad$ At 1.2 .

$56 \quad$ At 2.4 .

$57 \quad$ At 2.4 .

58 Cohort studies examine the relationship between exposure to a factor or factors and the probability of the occurrence of a disease by observing large numbers of people over a period of time and comparing incidence rates of the disease in relation to exposure levels.

59 Case control studies examine the relationship between an attribute and a disease by comparing those with and without the disease with respect to the presence of the attribute or level of exposure to it. 
with the individual's consent, should be made. ${ }^{61}$ Furthermore, the Guidelines provide that participants (and their main care provider) must be informed of any clinically significant abnormal laboratory results or clinical observations that are detected during the course of a study. ${ }^{62}$ Finally, where participants are found, through the conduct of a study, to have a previously undetected health care need that is not directly related to the study, the Guidelines state that arrangements should be made for the participant to receive the necessary care. ${ }^{63}$

The Guidelines provide researchers with explicit direction on how to address previously unknown health problems, and clinically significant abnormal results and observations. Many IFs will fit within one or both of these categories. Nevertheless, there are still issues left unresolved by the Guidelines. For example, it is not clear whether participants are supposed to be advised, during the informed consent process, of a researcher's obligation to disclose any clinically significant abnormal results or observations. It is possible that a participant would not want to be informed of such a finding, and would therefore refuse to participate in research on that basis. The nature of the information conveyed during the informed consent process is, therefore, an area that requires further investigation.

\section{Operational Standards for Ethics Committees}

The essential elements of informed consent to participate in a health research investigation are further detailed in the Ministry of Health's $(\mathrm{MoH})$ Operational Standard for Ethics Committees (Operational Standard). This document provides guidelines for the constitution and operation of ethics committees reviewing health and disability research, ${ }^{64}$ and derives its public authority from the terms of reference of ethics committees established under s 11 of the New Zealand Public Health and

\footnotetext{
61 National Ethics Advisory Committee Ethical Guidelines for Intervention Studies: Revised edition, above $\mathrm{n}$ 38, at 6.71; National Ethics Advisory Committee Ethical Guidelines for Observational Studies: Observational research, audits and related activities, above n 38, at 9.1.

62 National Ethics Advisory Committee Ethical Guidelines for Intervention Studies: Revised edition, above n 38 , at 6.68 .

At 6.70 .

Ministry of Health Operational Standard for Ethics Committees (Ministry of Health, Wellington, 2006) at 1.2.
} 
Disability Act $2000 .^{65}$ The Operational Standard provides that in order for adequate information to be provided to a person for the purpose of gaining their informed consent, the information provided should include: ${ }^{66}$

iv. all foreseeable risks, side-effects or potential harm that are material to the research participant, and how significant risks will be monitored and managed;

$\cdots$

xiii. the research participant's access to research findings;

xiv. the responsibilities of the researchers.

The Operational Standard therefore does not explicitly require information about IFs to be provided to a prospective participant during the informed consent process. The Operational Standard does, however, provide that in general, researchers should be required to immediately report all serious or unanticipated adverse events to the ethics committee. ${ }^{67}$ An adverse event includes an undesirable and unintended result of therapy or other intervention, ${ }^{68}$ and could therefore include the discovery of an IF. The Operational Standard does not, however, include an obligation to disclose the event to the research participant themselves.

\section{Health Information Privacy Code 1994}

Research involving the use of personal health information must comply with the Health Information Privacy Code 1994 (HIPC). ${ }^{69}$ 'Health information' includes information concerning: ${ }^{70}$

(a) information about the health of that individual, including his or her medical history; or

\footnotetext{
$65 \quad$ At 1.0 .

$66 \quad$ At 2.2 .

67 At 6.6 .

68 At 98 .

$69 \quad$ Health Research Council of New Zealand Guidelines on Ethics in Health Research (2005) at 4.1.

$70 \quad$ Health Information Privacy Code 1994, cl 4(1).
} 
(d) information provided by that individual in connection with the donation, by that individual, of any body part or any bodily substance of that individual or derived from the testing or examination of any body part, or any bodily substance of that individual; or

(e) information about that individual which is collected before or in the course of, and incidental to, the provision of any health service or disability service to that individual.

For the HIPC to apply to health research, the researcher must be a 'health agency', and the information must be 'health information'. If the research falls outside either of these definitions, the HIPC will not apply. ${ }^{71}$ Health information, has at the core of its definition, the notion that the information relates to an identifiable individual. ${ }^{72}$ IFs concern the health of an individual, as required by $\mathrm{cl} 4(1)(\mathrm{a})$, and therefore fit within the definition of 'health information'. Moreover, a researcher will be a 'health agency' if they provide health or disability services. ${ }^{73}$ Health and disability services include services provided to an individual for the purpose of improving or protecting the health of that individual or the public. ${ }^{74}$ The purpose of human subjects research is to create generalisable knowledge which advances the public good. ${ }^{75}$ Consequently, human subjects researchers are likely to fit within the definition of a 'health agency'.

Under the HIPC, an individual has rights of access to their own health information. ${ }^{76}$ In all situations other than where an individual seeks access to their own health information, r 11 applies. Rule 11 places limits on the disclosure of health information, and applies in situations where a health agency proposes to volunteer information to the individual or to a third party, or a third party has requested access to a person's health information. The underlying premise of this rule is that health agencies must not disclose individuals' health information unless they have good reason in terms of the exceptions

\footnotetext{
71 Health Research Council of New Zealand, above n 69, at 5.10.

72 At 5.10 .

73 Health Information Privacy Code, cl 4(2)(a).

$74 \quad$ Clause 3.

75 Pike, Rothenberg and Berkman, above n 20, at 41.

76 Health Information Privacy Code, r 6.
} 
that the rule provides. ${ }^{77}$ For the purposes of this paper, the following exceptions may be relevant: ${ }^{78}$

(1) A health agency that holds health information must not disclose the information unless the agency believes, on reasonable grounds, that -

(a) The researcher might disclose the information to the individual; or

(b) The individual concerned, or the individual's representative, may authorise disclosure; or

(2) Compliance with subrule (1)(b) is not necessary if the health agency believes on reasonable grounds that it is either not desirable or not practicable to obtain authorisation from the individual concerned and that -

(c) the disclosure of information is necessary to prevent or lessen a serious or imminent threat to -

(i) public health or public safety; or

(ii) the life or health of the individual concerned or another individual.

\section{University of Auckland Guiding Principles}

The majority of health research on human subjects requires ethics committee approval in order to proceed. The University of Auckland Human Participation Ethics Committee (UAHPEC) is one ethics committee that guides prospective researchers as to how they should address IFs. In its Guiding Principles for Conducting Research with Human Participants UAHPEC provides: ${ }^{79}$

UAHPEC uses the standard of more-than-minimal risk to identify incidental findings: if a contingency is more likely to arise due to participation in the study than it would in everyday life outside of the study, then it deserves special attention.

\footnotetext{
77 Health Research Council of New Zealand, above n 69, at 5.17.

78 Health Information Privacy Code, $\mathrm{r} 11$.

79 University of Auckland: Human Participants Ethics Committee Guiding Principles for Conducting Research with Human Participants (March 2013) at 5.13.
} 
Further, UAHPEC expects researchers to have clear policies and procedures in place to allow them to identify and address IFs. ${ }^{80}$ The researcher must indicate to UAHPEC how likely an IF may be, and how large the impact of the finding may be on the participant. ${ }^{81}$ If researchers believe there is a reasonable probability of IFs, they have a responsibility to inform the participant of this in advance. ${ }^{82}$ If a participant does not wish to be informed of such a finding, UAPHEC advises researchers that the participant should be excluded from the research. ${ }^{83}$

According to the UAHPEC policy, in the event of an IF, researchers are expected to advise the participant within the limit of their expertise and put the participant in contact with appropriate assistance. ${ }^{84}$ It appears that researchers are equally expected to apply this approach in the event of an unexpected IF. Consequently, a participant who had not been informed of the risk of a particular IF, as it was not considered reasonably probable, will nevertheless be advised of its presence. This approach raises a number of ethical issues, which will be discussed in Part IV.

\section{General Comments}

Whilst New Zealand comprehensively regulates human subjects research, there is an absence of guidance on how to manage IFs. Direction on the information researchers should provide to participants is inconsistent, and there is no clear process to be followed upon identification of an IF. Under the current framework, it is up to individual ethics committees, such as the UAHPEC, to individually implement policies relating to the management and disclosure of IFs. Furthermore, there is no indication whether a research participant may refuse to be told about IFs. Consequently, research participants are not necessarily receiving enough information to be fully informed, and provide informed consent for the purposes of the Code of Rights. More generally, under the current system, the rights and interests of research participants are not receiving sufficient protection.

\begin{tabular}{ll}
\hline 80 & At 5.13. \\
81 & At 5.13. \\
82 & At 5.13. \\
83 & At 5.13. \\
84 & At 5.13.
\end{tabular}




\section{Overseas Jurisdictions}

It is valuable to briefly examine how other states have regulated human subjects research and, in particular, IFs. The United States and the United Kingdom are both at the forefront of medical research, yet as will be shown, their frameworks for managing IFs are similarly ambiguous.

\section{United States}

Much of the legal discussion involving IFs in the United States (US) has been framed in terms of federal Common Rule requirements contained in the Code of Federal Regulations. ${ }^{85}$ Before a researcher conducts any research on a human subject, the Common Rule requires a researcher, during the consent process, to provide subjects with a description of any reasonably foreseeable risks or discomforts and a description of any benefits that may reasonably be expected from the research. ${ }^{86}$ The Common Rule does not, however, directly address the process to be followed when a researcher identifies an IF, nor the scope of disclosure to a research participant. Further, the Common Rule does not specify whether research participants may refuse to be told about IFs.

In the US, ethics committees are known as Institutional Review Boards (IRBs). In one study regarding IRB conduct and IFs, twenty-nine IRB Chairs were asked what information, if any, their IRBs required researchers to include in informed consent documents with respect to IFs. ${ }^{87}$ Only one Chair reported that their IRB had IF-specific requirements, yet described this requirement as relatively informal: ${ }^{88}$

To my knowledge it's not a formal requirement, but it is something that we do so routinely that it's become a de facto requirement... We always require a full statement of risk and this would include in genomic incidental findings the risk of job discrimination, the risk of, you know, future anxiety, concern and stress, emotional reaction to the news, risk of insurance loss.

\footnotetext{
85 Stacey A Tovino “Incidental Findings: A Common Law Approach" (2008) 15 Acc Res Pol Qua Ass 242 at 259. 
The remaining Chairs reported that their IRBs had no requirements relating to IFs or that their IRB requirements were "limited, indirect, and relatively generic." 89

Similarly to New Zealand, US regulations do no explicitly require researchers to discuss with participants the risk of IFs or the researcher's policy for disclosure of IFs. Individual IRBs are left to implement their own policies, with very few, it seems, addressing IFs specifically.

\section{United Kingdom}

Guidance on the management of IFs in the United Kingdom (UK) is inconsistent and difficult to find. ${ }^{90}$ Both the UK Department of Health and the National Research Ethics Service (NRES), however, require that research participants be made aware of possible disadvantages and risks of taking part in research. ${ }^{91}$ These risks include the discovery of another condition of which the participant is unaware, which might have medical or insurance implications. ${ }^{92}$ Participants must also be informed about the arrangements for dealing with such a discovery. ${ }^{93}$ Despite this, there is evidence of variations in understanding on the issue of IFs, and consequently in the management of findings. ${ }^{94}$

The NRES suggests that researchers explain to participants if their general practitioner (GP), or other health care practitioner, needs to be notified of their involvement and to seek consent for this notification. ${ }^{95}$ They further advise that researchers should explain to participants what information will be exchanged. ${ }^{96}$ Nevertheless, it is unclear from this statement whether the GP is informed merely that the participant has taken part in research, or whether the GP is informed of all results, including IFs.

The Medicines and Healthcare Products Regulatory Authority recommends that researchers have policies in place that facilitate the disclosure of IFs when identified in

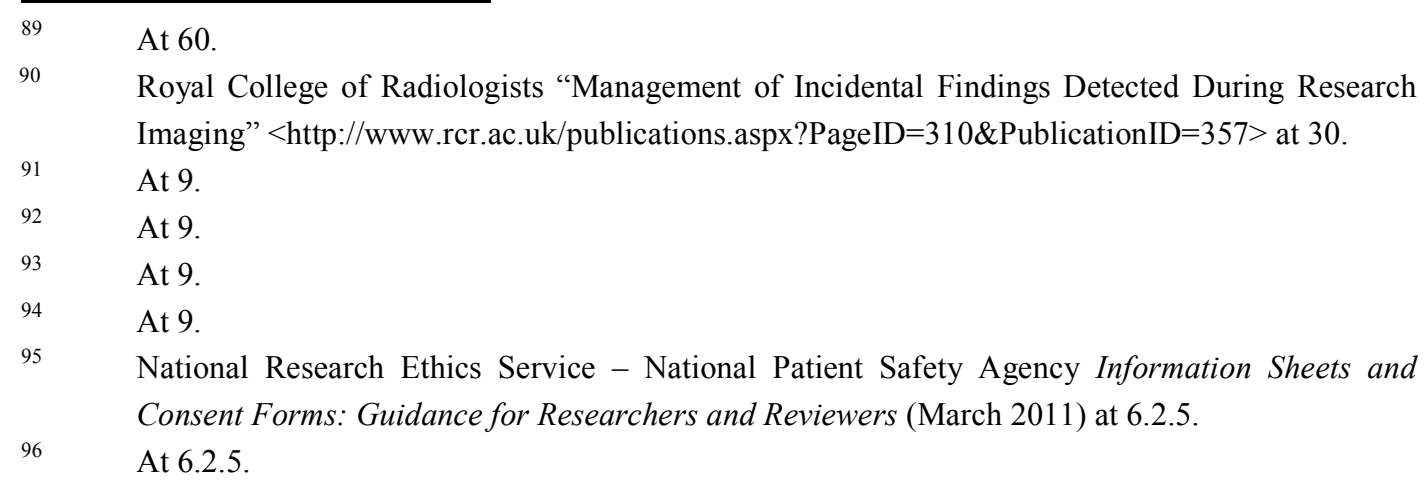


participants undergoing MRI. ${ }^{97}$ Furthermore the Authority provides this should be followed by appropriate onward referral. $^{98}$ There are no other explicit UK recommendations to disclose IFs to research participants unless the participant specifically requests disclosure. ${ }^{99}$ In such a case, the participant would have a right, under the Data Protection Act 1998, to have access to IFs. ${ }^{100}$

Therefore, in the UK, although researchers are required to warn prospective research participants of the risk of IFs, unless a participant explicitly requests disclosure, there is no law requiring IFs to be disclosed to them.

\section{Conclusion}

Current law and regulations, both in New Zealand and internationally, offer little direct guidance on how to address IFs in the research setting. In the majority of cases, any requirement to advise participants of the risk of IFs must be implied from a general obligation to advise of the risks of a research procedure. The nature and extent of information participants receive currently appears, in most cases, to be determined by the conducting research team and presiding ethics committee. This is unsatisfactory as, like has been illustrated in the US, participants will receive more or less information depending on the research team or ethics committee. If, when deciding whether to take part in a research procedure, participants do not receive all relevant information, they are not fully informed. Under New Zealand law, proceeding with research on this basis would amount to a breach of the Code of Rights. In order to improve this situation, a comprehensive regulatory framework guiding the management of IFs is required.

\section{Towards a Comprehensive Approach - Important Considerations}

As has been discussed above, the current lack of consensus and absence of uniform standards for IF management is problematic. The absence of a concrete regulatory framework can mean that researchers encountering IFs are uncertain about what to do with the information. Not only is current guidance unclear, but in many circumstances

\footnotetext{
97 Medicines and Healthcare Products Regulatory Authority Safety Guidelines for Magnetic Resonance Imaging Equipment in Clinical Use (December 2007) at 4.10.1.

$98 \quad$ At 4.10 .1 .

$99 \quad$ Booth and others, above n 16, at 460.

100 Data Protection Act 1998 (UK), s 7.
} 
the participant's wishes would not have be ascertained. In determining the most appropriate approach for the management of IFs however, a number of important issues require consideration. The next section of this paper will address these issues.

\section{A What to Disclose?}

Under the Code of Rights, a prospective research participant in New Zealand has a right to the information that a reasonable consumer, in that consumer's circumstances, would expect to receive. ${ }^{101}$ If a research participant does not receive this information, they are not adequately informed for the purposes of giving informed consent, and should not, therefore, partake in the research. ${ }^{102}$ The author has already proposed, that a reasonable consumer would expect to be advised about the possibility of IFs. Researchers should be required to discuss the potential for IFs with participants during the informed consent process. Researchers should also identify and discuss with participants any IFs that may reasonably be expected to flow from the research procedure. If an IF is not reasonably foreseeable, it need not be raised. Finally, during the informed consent process, the researcher should discuss with the participant the extent to which IFs will be disclosed. The following section focuses on this issue, and examines the various approaches to disclosure that could be adopted.

\section{Return no IFs}

There are a number of possible approaches to the determination of which IFs, if any, should be disclosed to a research participant. The first possibility is that researchers not return any IFs to participants, regardless of the seriousness of the finding. A strength of this approach is that it acknowledges the difficulties inherent in tracking down and locating large numbers of participants, and the large amounts of resources, both time and money, needed to analyse and return the thousands of variants that could arise in any given research participant's sample. ${ }^{103} \mathrm{~A}$ further advantage is that this approach allocates resources appropriately. Returning IFs diverts funds away from research, the purpose of which is to create generalisable knowledge that advances the public good. ${ }^{104}$

\footnotetext{
101 Code of Rights, sch, cl 2, right 6(2).

102 Schedule, cl 2, right 7(1).

103 Wolf, Paradise and Caga-anan, above n 30, at 364.

104 Pike, Rothenberg and Berkman, above n 20, at 41.
} 
These funds are redirected to the process of returning IFs, which generally only benefits particular individuals. ${ }^{105}$ Finally, this approach recognises the distinction between research and clinical care, and does not contribute to the therapeutic misconception. ${ }^{106}$ The idea of a therapeutic misconception involves the mistaken conflation of medical research with clinical care, ${ }^{107}$ and will be discussed in greater detail later in this part. ${ }^{108}$

This approach also has a number of disadvantages. First, given emerging ethical guidance that encourages the return of results in certain circumstances, and the fact that some researchers have already started returning IFs, it may be unrealistic to conclude that researchers should not return IFs, particularly where the IF is serious or lifethreatening. ${ }^{109}$ The reason that some researchers started returning IFs was because they felt morally bound to return those with significant health implications. ${ }^{110}$ Creating a standard whereby researchers are not expected to return IFs may consequently lead researchers to compromise their moral conviction. Moreover, this approach does not address a participants' reasonable expectations that someone with particularised knowledge and skills, who is granted access to otherwise private health information, would inform them of any significant health problems. ${ }^{111}$ For these reasons, not returning IFs irrespective of their severity is arguably unethical. ${ }^{112}$

\section{Return all research data without interpretation}

An alternative approach is an obligation to return all data without interpretation. This approach responds to arguments by some that participants prefer to receive significantly more information than has generally been returned, even if the information is not clinically actionable. ${ }^{113}$ Such an approach, though rarely considered, does have some advantages. First, it allows researchers to fulfil their moral convictions by returning information to participants while minimising the burden of doing so. At least in the case

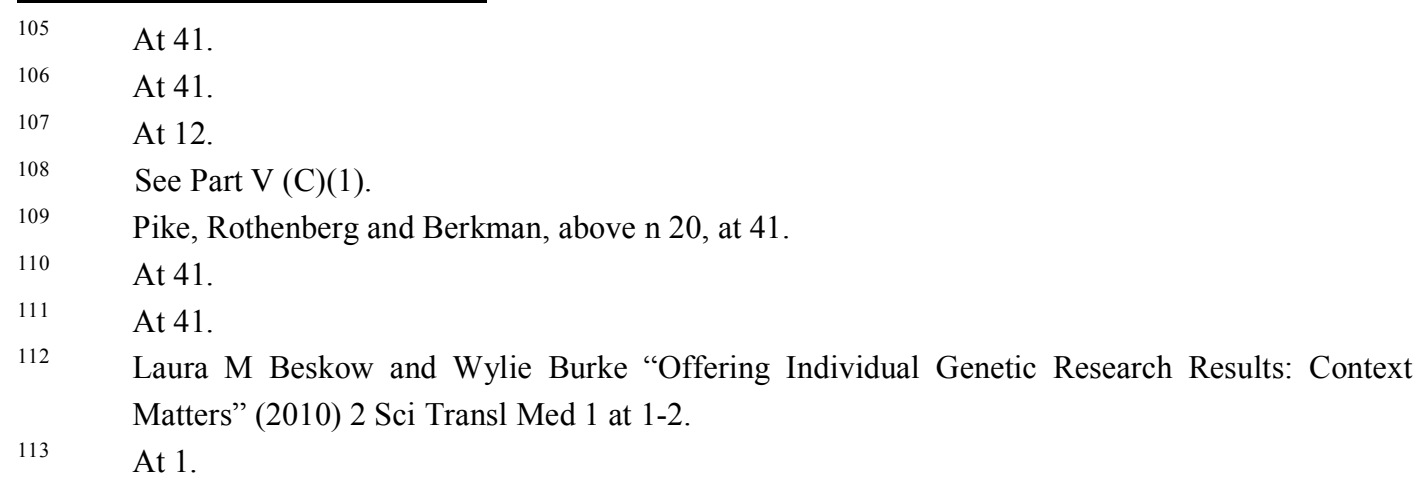


of genetic data, websites and services are increasingly allowing individuals to obtain reasonably priced interpretations, meaning that participants can control when and whether they learn more about their genetic information. ${ }^{114}$ This approach also removes any potential obligation to re-examine and re-notify participants with updated analyses as additional knowledge is acquired. ${ }^{115}$ Participants have access to their own data and can seek out their own re-examination in line with evolving science. ${ }^{116}$

This approach also has drawbacks. First, returning all data without interpretation may not satisfy a researcher's moral conviction, as they will not be responsible for alerting research participants to IFs that have significant health implications. ${ }^{117}$ Furthermore, handing information to participants without any interpretation may overwhelm those who do not know where to turn for interpretation, or who may get it interpreted without appropriate guidance about what the information means. ${ }^{118}$ Finally, returning all data to individual research participants may be technologically and logistically difficult and expensive, particularly where studies involve thousands of participants. ${ }^{119}$

Both full disclosure and complete nondisclosure of IFs are therefore problematic approaches. Failure to disclose medically relevant IFs cannot be ethically justified, and full disclosure, in addition to being costly and time-consuming, fails to ensure participants receive appropriate counselling and support in the interpretation of research data.

\section{Disclosure determined by clinical benefit}

A majority view is emerging among scholars, practitioners, and advisory bodies that researchers have an ethical obligation to offer to return some IFs. ${ }^{120}$ It has been submitted that IFs can be divided into three categories: those that offer strong net benefit and should be disclosed, those that offer possible net benefit and may be disclosed, and finally, those that are unlikely to offer net benefit and therefore should not be

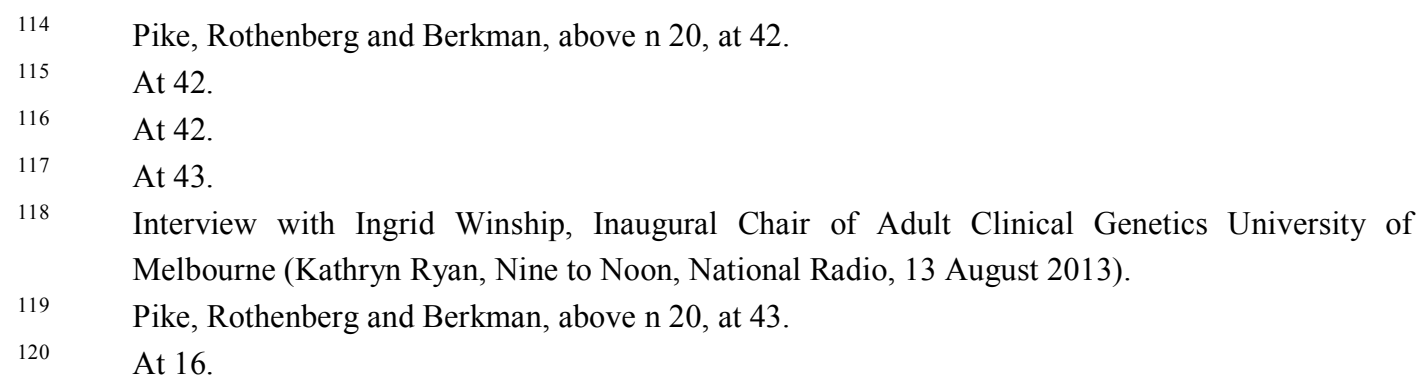


disclosed. ${ }^{121}$ The argument put forward by health professionals is that categorising disease types into these packages is an appropriate way to determine which IFs should be disclosed to participants. ${ }^{122}$

Nevertheless, these terms still leave a lot open for interpretation. ${ }^{123}$ For example, what constitutes a strong net benefit? Must the consequences be life and death? Or is a reduced chance of contracting a disease that causes discomfort sufficiently significant? Furthermore, must the IF have individual significance, or is reproductive significance sufficient? ${ }^{124}$

An IF whose disclosure offers strong net benefit can be defined as one revealing a condition likely to be serious or life-threatening that can be avoided or ameliorated. ${ }^{125}$ This category would also include genetic information that could be used in reproductive decision-making to avoid grave risk to offspring. ${ }^{126}$ Under this approach, the researcher should advise the participant of an intention to disclose an IF in this category during the informed consent process. In genetic studies, an IF of genes associated with hereditary cancer would be in this category, as it reveals a condition likely to be life threatening or to impose grave harm that may be avoided by alerting the research participant. ${ }^{127}$

An IF that offers possible net benefit is one that may offer more benefit than burden to a research participant. ${ }^{128}$ Researchers should discuss the possibility of revealing such IFs with participants during the informed consent process, where an approach should be agreed upon. ${ }^{129}$ This category includes genetic information revealing a significant risk of a condition likely to be grave or serious that cannot be avoided or ameliorated, but which a research participant is likely to consider important. ${ }^{130}$ An IF that indicates a participant's susceptibility to Alzheimer's disease at some point in the future would

$121 \quad$ Wolf and others, above $\mathrm{n} 5$, at 238.

122 Anne Townsend and others "“'I Want to Know What's in Pandora's Box": Comparing Stakeholder Perspectives on Incidental Findings in Clinical Whole Genomic Sequencing” (2012) 158 Am J Med Genet A 2519 at 2523. Pike, Rothenberg and Berkman, above n 20, at 15.

At 15 .

Wolf and others, above $\mathrm{n} 5$, at 238 .

At 238 .

At 238 .

At 238 .

At 239 .

At 239 . 
come within this category. ${ }^{131}$ This category also includes genetic information of a condition likely to be serious that can be used in reproductive decision-making to avoid significant risk for offspring. ${ }^{132}$

Finally, IFs that are unlikely to have net benefit should not be disclosed to research participants. ${ }^{133}$ The rationale behind withholding disclosure is an absence of a justification for subjecting the research participant to the anxiety and burden of receiving this information. ${ }^{134}$ A participant should be advised of a policy against disclosure during the informed consent process. ${ }^{135}$ In this category are IFs that are not likely to be of serious health or reproductive importance. ${ }^{136}$ An IF of misattributed paternity would usually fall within this category. ${ }^{137}$

The balance between the risk and benefit of disclosing IFs, therefore, depends on the significance of findings in the diagnosis of disease and the impact of early intervention on outcome. ${ }^{138}$ Early identification of an IF might be of unequivocal benefit to the participant if the condition is treatable and early diagnosis improves the outcome. For example, renal cell carcinoma, a common type of kidney cancer, can be detected earlier with imaging than at symptomatic presentation, with a consequent significant improvement in prognosis. ${ }^{139}$ Many incidental neuroimaging findings are, however, of indeterminate clinical significance, ${ }^{140}$ with poorly characterised natural history and unpredictable individual outcomes; thus, treatment is of questionable benefit. ${ }^{141}$

Despite the view of many health professionals that categorising disease types is an appropriate way to determine which IFs should be disclosed, public attitudes indicate

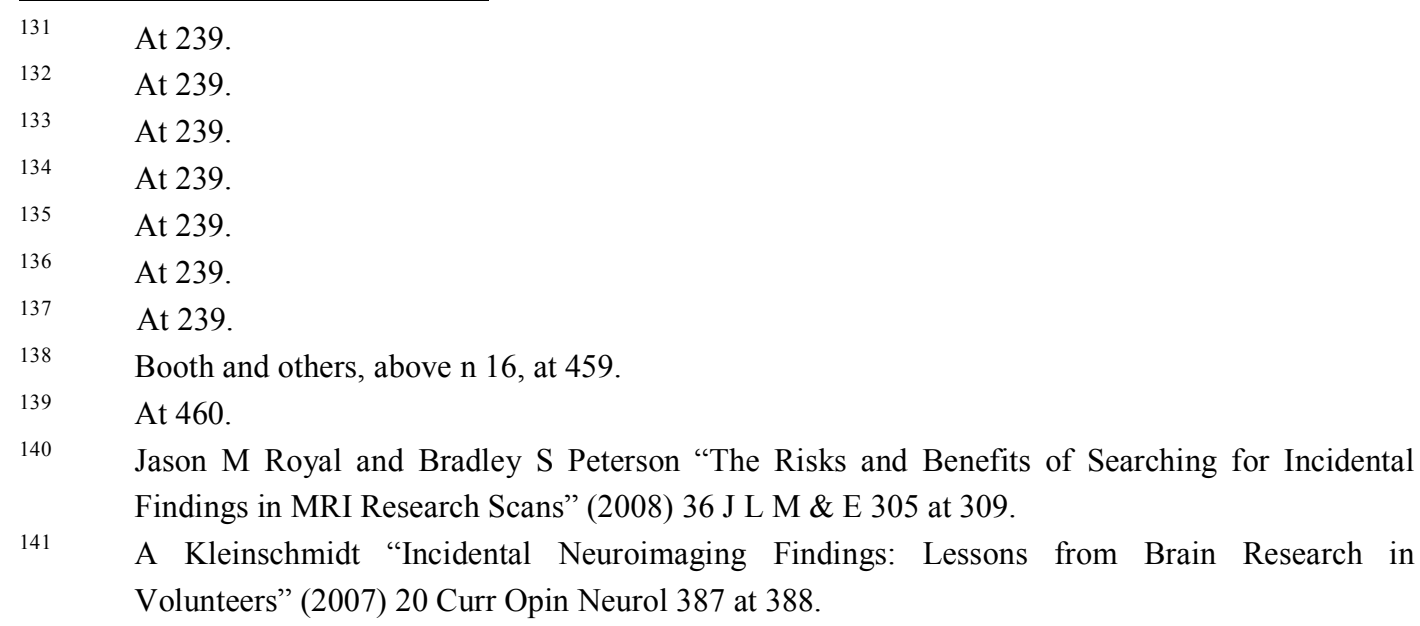


that disclosure should not be based on clinical indicators alone. ${ }^{142}$ Members of the public have emphasised the subjectivity of such categorisations. ${ }^{143}$ It is argued that as individuals interpret "relevance" and "seriousness" differently, participants should not be presented with pre-categorised packages that have been filtered by professionals. ${ }^{144}$ Research has shown that the public's preference is for disclosure of IFs in general. ${ }^{145} \mathrm{~A}$ recent study surveying public attitudes to IFs from hypothetical testing found that 69 per cent of the public wanted information about IFs where the risk of the IF was unclear. Nevertheless, 96 per cent of respondents wanted information about serious and treatable diseases, ${ }^{146}$ thus lending support to the profession's proposal to categorise findings.

For the public, the importance of personal choice was associated with ownership. One study participant questioned why it was even an issue of the doctor having a say, as it is the individual's body. ${ }^{147}$ Participants indicated the importance of control and that nobody was entitled to make decisions for them: ${ }^{148}$

... we get back to the whole issue of choice. Whose position is it to dictate what kind of knowledge we have about ourselves, whether it's medical or otherwise? ... Not to have that choice to know about yourself. That... is an element of control that I don't want anybody having other than me.

The difficulty with this approach, however, is determining at what point a participant makes their disclosure decisions. Realistically, this must take place during the informed consent process. If it were left until after the research had been conducted, researchers would presumably not seek a participant's preference unless they had in their possession knowledge of IFs that they believed warranted disclosure. Consequently, participants may become concerned as to why a researcher is seeking their preference, and may feel obliged to elect for disclosure.

\footnotetext{
142 Townsend and others, above n 122, at 2521.

143 At 2523

144 At 2521 .

145 At 2523 .

146 S B Haga and others "Public Attitudes toward Ancillary Information Revealed by Pharmacogenetic Testing under Limited Information Conditions" (2011) 13 Genet Med 723 at 723.

147 Townsend and others, above n 122, at 2521.

$148 \quad$ At 2521
} 
Although health professionals support participant choice, it has been emphasised that what participants want to know should be balanced against what information they are entitled to have. ${ }^{149}$ On this point, it is argued that participants should have a "reasonable" amount of freedom in deciding what information will be disclosed to them. ${ }^{150}$ This argument is based on logistics, and the fact that resources are not yet sufficient to analyse all data that is received, and return it in an understandable way. ${ }^{151}$ Health professionals also feel that full disclosure will mean sharing data of unknown significance that could be burdensome or meaningless for participants. ${ }^{152}$

What can be taken from this is that there is a feeling within the public that participant choice, underpinned by autonomous decision-making, and not clinical benefit should be the criterion for disclosure of IFs. ${ }^{153}$ Conversely there is agreement within the body of health professionals that clinical benefit should be the determining factor in the extent to which IFs are disclosed to research participants.

\section{An obligation to search for IFs?}

Assuming there is some obligation to disclose certain IFs that are discovered in the course of research, the next question is whether there ever is or should be a positive obligation to search for these findings? In other words, when researchers generate and analyse data, do they have an obligation to actively look within the data for potential indications of disease ${ }^{154}$ Whilst the standard view has been that researchers generally have no obligation to act as health professionals and actively search for IFs, but this assumption appears to be changing. ${ }^{155}$ This gives rise to a fourth potential approach to IF disclosure, involving researchers returning a pre-determined selection of IFs listed in a compendium.

\footnotetext{
$149 \quad$ At 2521.

$150 \quad$ At 2521 .

151 At 2521 .

$152 \quad$ At 2521 .

153 At 2522.

154 Catherine Gliwa and Benjamin E Berkman "Do Researchers Have an Obligation to Actively Look for Genetic Incidental Findings?” (2013) 13 Am J Bioeth 32 at 33.

155 Wolf and others "Managing Incidental Findings in Human Subjects Research: Analysis and Recommendations" (2008) 36 J L M \& E 236 at 238.
} 
This approach is gaining popularity in genetic research, with a number of groups having discussed the possibility of building standard lists of genetic variants that could or should be disclosed as IFs. The American College for Medical Genetics (ACMG), for example, recommends that for any evaluation of clinical sequencing results, a minimum list of 57 conditions, genes and variants should be examined and the results disclosed. ${ }^{156}$ The conditions are those that the ACMG considers most likely to be verifiable by other diagnostic methods and amenable to medical intervention. ${ }^{157}$ It is estimated, from a limited amount of published data, that approximately one per cent of genetic sequencing reports will include an IF from this list. ${ }^{158}$

In support of guidelines such as those proposed by the ACMG, it has been said that they "represent an initial attempt to set a professional standard for best laboratory practices that will responsibly minimise variation in laboratory analysis and reporting of clinically beneficial IFs." 159 While this approach establishes an obligation on the part of the researchers to search for findings, it is argued that the obligation is narrow and confined to those specific variants that are well characterised and understood. ${ }^{160}$ This approach is also likely to satisfy a researcher's moral convictions about returning IFs with important health implications.

While most agree that there need to be standards, critics say that the recommendations run afoul of personal autonomy, ${ }^{161}$ and that returning IFs without participant consent is misguided. ${ }^{162}$ This is because the recommendations do not consider participant

\footnotetext{
156 American College of Medical Genetics and Genomics "ACMG Recommendations for Reporting of Incidental Findings Clinical Exome and Genome Sequencing” (2013) $<$ http://www.acmg.net/docs/ACMG_Releases_Highly- 
preferences in reporting results. Under the ACMG approach, participants will receive all recommended results whether or not they have expressed a preference. ${ }^{163}$

This approach would also be labour intensive. Each list's content would need to be regularly re-examined and modified, in order to remain consistent with evolving science. ${ }^{164}$ As compendia would evolve over time, it is unclear whether researchers would have an ongoing obligation to re-examine participant data in light of changes to the compendium. ${ }^{165}$ Furthermore, there would likely be an increase in the costs associated with research procedures. ${ }^{166}$ As these costs would not necessarily relate to the object of the study, it is unclear where this additional funding would come from. Those who fund research projects may be reluctant to contribute more money so that individual participants can be tested for specific health conditions.

Finally, it is argued that this approach gives a new meaning to the term 'incidental finding,. ${ }^{167}$ Rather than reporting findings that are incidental to the purpose of the research, laboratories will be undertaking a deliberate search for pathogenic or likely pathogenic indicia. Even this level of return may contribute to the therapeutic misconception, with research participants relying on researchers and the research process in a way that was not intended. ${ }^{168}$

Similarly in the imaging context, it has been argued that radiologists should be engaged to read all scans. ${ }^{169}$ This would provide the surest means of protecting participants from unidentified but potentially life-threatening conditions that may appear as IFs. ${ }^{170}$ Resistance to routine readings by radiologists has been fuelled in part by the cost, both financial and logistical, of engaging radiologists to analyse all scans. ${ }^{171}$ An associated reality is that the costs of such a policy may, in the future, determine which researchers

163 Megan Allyse and Marsha Michie "Not-so-incidental findings: the ACMG recommendations on the reporting of incidental findings in clinical whole genome and whole exome sequencing" (2013) 30 TIBTEC 1 at 1. Gliwa and Berkman, above n 154 at 40. Mildred K Cho "Understanding Incidental Findings in the Context of Genetics and Genomics" (2008) 36 J L M \& E 280 at 283. Allyse and Michie, above n 163, at 1.

At 1 .

Pike, Rothenberg and Berkman, above n 20, at 45. Royal and Peterson, above n 140, at 305. At 305 . At 305 . 
can conduct research, and whether projects actually receive required levels of funding. ${ }^{172}$ Nevertheless, such readings would maximise benefits and minimise risk to participants, as they would provide the best chance for IF identification. ${ }^{173}$ Many imaging researchers accept the validity of this argument, but also acknowledge the logistical and financial difficulties that accompany it. ${ }^{174}$

\section{A Right not to Know?}

Discussion up until this point has proceeded largely on the assumption that the researcher or research team is responsible for determining the extent to which IFs are disclosed to research participants. But what gives them this right? To the contrary, respect for the autonomy of the research participant suggests that the participant, not the research team, should have the discretion to decide whether or not an IF is disclosed. ${ }^{175}$ If a participant has explicitly indicated that he or she does not wish to receive information regarding IFs, should individual autonomy take precedence over a researcher's desire to discharge their perceived ethical obligation by disclosing a clinically relevant IF?

These questions raise the issue of a right not to know information about oneself, and offer a further reason why caution should be exercised in the disclosure of IFs in the research setting. The right not to know is a well-established element of modern medical ethics and medical law. ${ }^{176}$ The Council of Europe's Convention on Human Rights and Biomedicine, for example, provides that "everyone is entitled to know any information collected about his or her health. However, the wishes of individuals not to be so informed shall be observed." ${ }^{\prime 17}$ The right not to know applies not only to patients but also to research participants. The Additional Protocol to the Convention provides: ${ }^{178}$ 
If research gives rise to information of relevance to the current or future health or quality of life of research participants, this information must be offered to them... In communication of such information, due care must be taken in order to protect confidentiality and to respect any wish of a participant not to receive such information.

The CIOMS and other international guidelines also recognise that the wishes of individuals not to be informed should be respected. ${ }^{179}$

The impact of IF disclosure depends on the circumstances and values of the person concerned. As a result, it is argued that it is ethically right that it is the individual participant who decides whether or not they wish to know the results of medical research. ${ }^{180}$ Even if treatment exists and, from a medical point of view, it may thus seem irrational to limit one's options by not knowing about a health condition, it is nevertheless argued that the decision whether or not to obtain information rests with the individual alone, ${ }^{181}$ and only in exceptional circumstances may restrictions be placed by law on the interests of the participant. ${ }^{182}$

In some contexts, however, the right not to know can become highly problematic. Consequently, it is doubtful whether a strict adherence to the right not to know is feasible. ${ }^{183}$ For example, the situation can become particularly troubling if a researcher has reason to believe that an IF threatens the research participant's life and has the potential to be dangerous for other persons. In such circumstances, the conflict between the principles of personal autonomy and non-malfeasance becomes evident. ${ }^{184}$ The question then becomes whether it is possible to avoid the described conflict of principles or, if this is not the case, how the conflict should be resolved. ${ }^{185}$

The WMA, which represents approximately 80 national medical associations, including New Zealand, does not respect refusal by an individual to receive IFs if disclosure is

\footnotetext{
$179 \quad$ Booth and others, above n 16, at 460.

180 Heinrichs, above n 6, at 61.

181 At 61.

182 Convention on Human Rights and Biomedicine, art 10.3.

183 Heinrichs, above n 6, at 61.

184 At 61.

185 At 61 .
} 
"required for the protection of another person's life."186 An example of such a situation would be a potentially epileptogenic brain tumour in a bus driver who happened to be a research participant. ${ }^{187}$ Even if this person did not wish for findings to be disclosed to them, according to the WMA, there would be an ethical duty to do so, with lives of others being put at risk if the IF is left undisclosed. ${ }^{188}$

Some writers have argued that an insistence on the right not to know by potential research participants should be an exclusion criterion. ${ }^{189}$ This would mean that people who do not wish to be informed of IFs would be unable to take part in the research. This solution incorrectly assumes, however, that a person is held to what they agree to during the informed consent process. ${ }^{190}$ Just as a participant is able to withdraw consent to a procedure, ${ }^{191}$ the health consumer focus in the Code of Rights suggests that participants would also be able to alter their preferences relating to IF disclosure. Taking the right not to know as an exclusion criterion may raise a further problem. Generally, only scientific parameters relevant to the experiment can serve as exclusion criteria in research projects. ${ }^{192}$ To draw on other facts could be seen as a form of discrimination. ${ }^{193}$ It therefore seems preferable to look for a different approach.

The aforementioned ACMG recommendations are an example of where participant preference is not taken into account when determining whether IFs are disclosed. Whilst recognising that this approach may violate existing ethical norms regarding personal autonomy, the ACMG felt that in selecting a minimal list weighted toward conditions where prevalence was high and intervention may be possible, there existed a fiduciary duty to prevent harm by warning participants, and that this principle superseded concerns about autonomy. ${ }^{194}$ The ACMG recommendations consequently provide that laboratories seek and report findings from the pre-determined list without reference to

At 461.

Heinrichs, above n 6, at 61.

At 61 .

Code of Rights, sch, cl 2, right 7(7).

Heinrichs, above n 16, at 61.

At 61

American College of Medical Genetics and Genomics, above n 156, at 11.
} 
participant preferences. ${ }^{195}$ Participants have the right to refuse consent to the procedure if they judge the risks of possible discovery of IFs to outweigh the benefits of testing. ${ }^{196}$

Once one acknowledges that it will sometimes be impossible to avoid a conflict between the principles of self-determination and non-malfeasance an alternative approach becomes clear. This approach requires the possibility of conflicts of principles to be made explicit during the informed consent process. ${ }^{197}$ Potential research participants should be informed that they have a right not to know and that researchers will respect this right unless concealing an IF could be immediately life threatening or comparably dangerous for them or third persons. ${ }^{198}$ Research participants should be made aware that in such cases the principle of non-malfeasance would outweigh their right to informational self-determination. On this basis, the participant should decide whether or not they want to participate in the research project. This approach has the benefit of establishing the circumstances in which the right not to know will be suspended. By doing so, it avoids the need to re-consult participants to ask them whether they adhere to their initial decision, and in doing so implying there is something that should be revealed. $^{199}$

This approach accords with that contained in the HIPC. As already discussed, r 11 of the HIPC places limits on the disclosure of health information. ${ }^{200}$ The underlying premise of this rule is that health agencies must not disclose individuals' health information unless they have good reason in terms of the exceptions that the rule provides. ${ }^{201}$ The rule provides an exception where the researcher discloses the information to the individual concerned. $^{202}$ Therefore in circumstances where concealing an IF could be immediately life threatening or comparably dangerous for the individual or a third party, disclosure of the IF to the individual despite an individual "opting-out" of disclosure will not amount to a breach of the HIPC.

\footnotetext{
195 At 9 .

196 At 9.

197 Heinrichs, above n 16, at 62.

198 At 62.

199 Heinrichs, above n 16, at 62.

$200 \quad$ See Part III (B)(4).

201 Health Research Council of New Zealand, above n 69, at 5.17.

202 Health Information Privacy Code, r 11(a).
} 
Including an "opt-out" provision in the informed consent document, whereby participants can choose not to have IFs disclosed to them, and accompanying this with a discussion on when, nevertheless disclosure of IFs will be made, may therefore strike an appropriate balance between personal autonomy and non-malfeasance. Although a default obligation to disclose clinically beneficial IFs is arguably most desirable from a researcher's perspective, it is, nevertheless, important to give deference to individual autonomy.

\section{Misattributed Paternity}

The most common IF in genetics research is misattributed paternity. ${ }^{203}$ For years, partial or complete non-disclosure of such findings has been the most common practice in both the clinical and research settings. ${ }^{204}$ For example, if a husband is found not to carry a genetic mutation that affects a child born to his wife, he is frequently told only that the recurrence risk is very low. ${ }^{205}$ The wife, however, may be told individually about the finding of misattributed paternity, which she can then address as she sees fit. ${ }^{206}$ Nondisclosure is even more common in the research setting. ${ }^{207}$ The foundations of this practice lie in a researcher's concern that revealing misattributed paternity will disrupt the family, as well as a desire to avoid getting involved in difficult situations. ${ }^{208}$ This approach has been criticised for undermining the man's and child's right to know about their biological connections. ${ }^{209}$

As misattributed paternity is the most common IF in genetics research, it is reasonable to expect researchers to warn prospective participants about the risk of uncovering such a finding. Ethics committees increasingly do, in fact, require the possibility of discovering misattributed paternity to be included in research consent forms. ${ }^{210}$ With knowledge of this possibility, individuals are better equipped to make an informed decision as to

\footnotetext{
203 K G Anderson "How Well Does Paternity Confidence Match Actual Paternity? Evidence from Worldwide Nonpaternity Rates" (2006) 47 Curr Anthropol 513 at 514.

204 Wright Clayton, above n 4, at 288.

205 At 289.

206 At 289.

207 At 289.

208 At 289.

$209 \quad$ At 289.

210 M DeCamp and J Sugarman "Ethics in Population-Based Genetic Research" (2004) 11 Account Res 1 at 23.
} 
whether or not to participate in the research. ${ }^{211}$ If genetic testing does reveal an IF of misattributed paternity, the author proposes that the same standard should be applied to this IF as any other. If disclosure is to be determined by clinical benefit, for example, this approach should also be applied to an IF of misattributed paternity.

\section{B Parties involved in disclosure}

Once it has been determined that an IF warrants disclosure, the regulatory framework should also detail who is responsible for disclosure, and to whom disclosure should be made.

\section{Who should disclose IFs?}

There appears to be consensus, internationally, that a researcher is not the appropriate person to disclose IFs to a research participant. In New Zealand, the Ethical Guidelines for Intervention Studies stipulate that: ${ }^{212}$

Where findings obtained by an intervention study suggest serious disease, study participants who have not already given permission for the transfer of the information to their medical advisor should be urged to seek further advice and advised of any potential consequences of not seeking such advice.

Furthermore, the American Society of Human Genetics and the Canadian College of Medical Geneticists both hold that the results of DNA analyses should be reported to an appropriate health professional who, in turn, has the responsibility of informing individuals of their presence and their meaning. ${ }^{213}$ In France, the National Consultative Ethics Committee for Health and Life Sciences recommends "the results of the tests be communicated in person by a physician whose competence permits a full explanation of the significance of the results." 214 In the UK, the Department of Health regulations do

\footnotetext{
$211 \quad$ Wright Clayton, above n 4, at 289.

212 National Ethics Advisory Committee Ethical Guidelines for Intervention Studies: Revised edition, above n 38 , at 7.9 .

213 American Society of Human Genetics, above n 213, at 782; Canadian College of Medical Geneticists "Policy statement concerning DNA banking and molecular genetic diagnosis" (1991) 14 Clin Invest Med 363 at 364. recommendations on 'genetics and medicine: from prediction to prevention"” (October 1995) $<$ http://www.ccne-ethique.fr/fr/node/714>.
} 
not state how IFs are to be communicated, but the implication is that the participant's GP should be involved. ${ }^{215}$ In Europe, the Additional Protocol to the Convention states that relevant IFs should be disclosed within a framework of healthcare or counselling, with an appropriate clinical professional supervising the research, but not explicitly disclosing any results themselves. ${ }^{216}$ Based on these authorities, it could be argued that the participant's GP, or at the very least a doctor assigned to the research team is the appropriate person to disclose IFs . ${ }^{217}$

Benefits of making GPs responsible for IF disclosures include the fact that GPs are likely to have more established relationships with their patients, and should therefore have a greater understanding of their individual needs. ${ }^{218}$ Consequently, in passing information onto a participant's GP, researchers may feel that they have more adequately discharged any ethical obligation related to disclosure. This view is adopted by the ACMG who, in their aforementioned recommendations, ${ }^{219}$ provide that it is the research participant's GP who will disclose the presence of an IF to the participant. ${ }^{220}$ This is based on the belief that the GP will be able to contextualise any IFs for their patient in light of personal and family history, physical examination or other relevant findings. ${ }^{221}$ The ACMG's rationale for placing responsibility for managing IFs with the GP reflects a wider understanding that the doctor-patient interaction is the appropriate place for such information to be explained and discussed. ${ }^{222}$ Lending further support to this argument, a study on expectations of participants in neuroimaging research found that a majority of research participants would prefer to learn about an IF from a doctor

\footnotetext{
$215 \quad$ Booth and others, above n 16, at 461.

216 European Additional Protocol to the Convention on Human Rights and Biomedicine, concerning Biomedical Research, art 27.

B M Knoppers and others "The Emergence of an Ethical Duty to Disclose Genetic Research Results: International Perspectives” (2006) 14 Eur J Hum Genet 1170 at 1175.

ACMG Recommendations for Reporting of Incidental Findings in Clinical Exome and Genome Sequencing (National Advisory Council for the Human Genome, 2013) $<$ http://www.youtube.com/watch?v=3N0qdg_YYbA $>$.

219 See Part V (A)(4).

220 American College of Medical Genetics and Genomics, above n 156, at 9.

$221 \quad$ At 9 .

222 At 9 .
} 
on the research team, instead of the researcher themselves. ${ }^{223}$ Part of the motivation for this was that the participants wanted somebody who could answer their questions. ${ }^{224}$

Nevertheless, there are still proponents of the view that, whenever IFs are to be disclosed, they should be disclosed directly to the research participant. These people believe that disclosure to the participant's GP gives the research participant no control over the information and compromises their right to privacy. ${ }^{225}$ The GP is likely to record the information on the participant's medical record before consulting with the participant, and it is argued that this chain of events is not consistent with respect for the research participant and their decisional autonomy. ${ }^{226}$ Proponents of this view believe that the research participant should control the information, and decide whom to consult. $^{227}$

In weighing these arguments, the author submits that there is a stronger basis for charging a participant's GP with the responsibility of disclosing the presence of IFs. Consequently, research consent forms should ask for the contact information of a participant's GP, so that, if necessary, they can be provided with information relating to IFs. $^{228}$ In providing these contact details, a participant is impliedly authorising the disclosure of IFs to their GP. In many research settings it may, in fact, already be necessary to have a GP's contact details, so researchers can advise the GP of their patient's participation in the research. This approach may encounter difficulties where a participant is not registered with a particular GP, or medical centre. In such circumstances, a doctor assigned to the research team should be responsible for disclosure, with this approach communicated to the participant during the informed consent process.

\section{Rights of family members}

In general, health information should not be disclosed without the authorisation of the

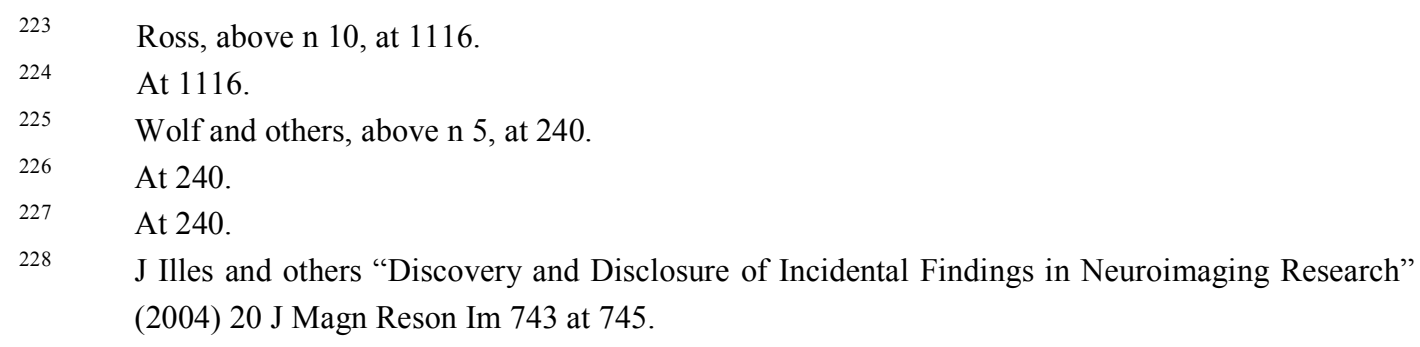


individual concerned. ${ }^{229}$ However, if an IF will affect other people in a community, for example, biological family members, do they have a right to be informed? This is a privacy issue concerning the confidentiality of a research participant's health information. ${ }^{230}$ In such situations, a conflict may arise between a participant's right to privacy and the right of their family to know information that may also affect them.

Several countries have issued guidelines to research and medical communities that recognise the utility of research results for family members. These guidelines often recommend providing results to relatives even when the information would otherwise be confidential. $^{231}$ The Tri-Council Policy Statement (TCPS), which governs federally funded research in Canada, now recognises circumstances when the results of research can be disclosed to the family of a research participant. Although the TCPS provides that participants should be given the opportunity to decide whether family are informed of genetic information, it notes that preferences may be subject to overriding considerations that warrant disclosure of information to relatives in exceptional circumstances. ${ }^{232}$ A situation where genetic research reveals information about a serious or life-threatening condition that can be prevented or treated through intervention is one such circumstance. ${ }^{233}$ What amounts to a "serious or life-threatening" condition however is unclear. ${ }^{234}$

Similarly in Australia, the National Statement on Ethical Conduct in Human Research permits disclosure to family without the participant's consent only if "the research discloses that a family member may be at risk of a life-threatening or serious illness for which treatment is available or pending." ${ }^{, 235}$ This permission comes with a caveat however; the participant's consent must first be sought for the disclosure of the

\footnotetext{
$229 \quad$ Health Research Council of New Zealand, above n 69, at 5.19.

230 Lee Black and Kelly A McClellan "Familial Communication of Research Results: A Need to Know?” (2011) 39 J L M \& E 605 at 606.

231 At 606 .

232 At 606.

233 Canadian Institutes of Health Research, Natural Sciences and Engineering Research Council of Canada, Social Sciences and Humanities Research Council of Canada Tri-Council Policy Statement: Ethical Conduct for Research Involving Humans (December 2010) at 183. Black and McClellan, above n 230, at 607.

235 National Health and Medical Research Council, Australian Research Council, Australian ViceChancellors Committee National Statement on Ethical Conduct in Human Research (March 2007) at 44.
} 
information. Their refusal then authorises disclosure without consent in these limited circumstances.

The UK takes a different approach when it comes to information uncovered in a research context. The Medical Research Council states only that "[p]articipants should be advised of the possible implications of genetic information for family members and the potential impact on family relationships. ${ }^{, 236}$ The guidance therefore does not support researcher disclosure directly to participants' families. This is a common position, but one that limits the avenues for discovery of information by potentially affected relatives. ${ }^{237}$

New Zealand sets a comparatively high bar for the disclosure of health information to someone other than the person to which the information relates. Whilst the HIPC emphasises that, in general, health information should not be disclosed without the authorisation of the individual concerned, it is recognised that it may not always be possible or desirable to obtain individual consent. ${ }^{238}$ The HIPC provides an exception to the requirement of authorised disclosure in situations where: ${ }^{239}$

(d) the disclosure of information is necessary to prevent or lessen a serious or imminent threat to -

(iii) public health or public safety; or

(iv) the life or health of the individual concerned or another individual.

In order to disclose health information under this exception, a researcher needs to believe on reasonable grounds that it is not practicable or desirable to obtain individual authorisation, and that: ${ }^{240}$

(1) there is a serious threat to public health, public safety or the life or health of an individual;

(2) the threat is imminent;

(3) the disclosure of the information would prevent or lessen that threat; and Medical Research Council Human Tissue and Biological Samples for Use in Research: Operational and Ethical Guidelines (April 2001) at 20.

Black and McClellan, above n 230, at 607.

Health Research Council of New Zealand, above n 69, at 5.19.

Health Information Privacy Code, r 11(2)(d).

Privacy Commissioner Health Information Privacy Code 1994: Incorporating amendments and including revised commentary, at 65 . 
(4) the disclosure of the information is necessary to prevent or lessen the threat.

New Zealand law therefore permits the disclosure of IFs in situations where it is not practicable or desirable to gain an individual research participant's consent to disclose IF information, but it is nevertheless deemed necessary, in order to, for example, prevent serious and imminent harm to the individual's family. The HIPC provides that the disclosure must be made to a person who can do something to prevent or lessen the threat. ${ }^{241}$ Disclosing an IF to a family member would, in many situations, satisfy this requirement, as they are likely to be the individual whose life or health is imminently threatened and will be capable of acting to prevent or lessen the threat. The extent of disclosure is restricted to that necessary to prevent or lessen the threat. ${ }^{242}$ Researchers will therefore need to determine how much information needs to be disclosed to serve this purpose.

There is, therefore, a growing consensus that where information is important for the health and wellbeing of relatives of participants and consent is not practicable or desirable, this information should be disclosed. ${ }^{243}$ The New Zealand law sets a high bar, and only permits disclosure in extreme circumstances, but does not require consent for disclosure to be first sought from the individual concerned. The author submits that the consent of a participant should, wherever possible, be sought before information relating to IFs is disclosed to family members. Only if seeking the individual's consent is not possible, or they refuse to disclose the information themselves, should disclosure without consent be considered.

\section{IFs and Tikanga Māori}

Most discussions on the return of IFs to date have been based on the idea that genetic, brain and other physiologic and biologic data is personal property. ${ }^{244}$ Individual ownership of genes and human tissue is based on Western ideas of individualised property. ${ }^{245}$ Some communities, however, may not view genes as personal property, but

\footnotetext{
$241 \quad$ At 65.

242 Health Information Privacy Code, r 11(3).

243 Black and McClellan, above n 230, at 607.

244 Elana Brief, Jennifer Mackie and Judy Illes "Incidental Findings in Genetic Research: A Vexing Challenge for Community Consent” (2012) 13 Minn J L Sci \& Tech 541 at 544.

$245 \quad$ At 543.
} 
as cultural heritage ${ }^{246}$ or collective inheritance. ${ }^{247}$ This begs this question, how can researchers uphold Western ethical standards relating to individual medical information and simultaneously honour cultural values that may conflict with those standards? ${ }^{248}$

As genetic research becomes more widespread, there is concurrent increasing demand to undertake genetic research on Māori. ${ }^{249}$ Māori are regarded by some in the research community as providing an ideal founder population, with well-described lineages and a high incidence of genetic diseases amenable to study. ${ }^{250}$ However genetic research is an area of prime sensitivity for Māori because of its association with whakapapa. ${ }^{251}$ Māori and other indigenous peoples generally consider body tissue to be tapu. ${ }^{252}$ Researchers undertaking medical research that involves the body, or any part of the body, such as organs, blood, hair, saliva, or other tissue, must therefore act in a respectful manner.

The Guidelines for Researchers on Health Research Involving Māori were developed to assist research teams in developing research projects in a culturally appropriate way and in a way that is responsive to Māori. ${ }^{253}$ The Guidelines provide that research must be undertaken in a culturally sensitive and appropriate manner in full discussion and partnership with research participants. ${ }^{254}$ Moreover, the Guidelines state that informed consent should, in many cases, be gained from both individuals and representative organisations, for example whānau, hāpu or iwi. ${ }^{255}$

Already established processes may aid researchers in the development of culturally appropriate policies for the return of IFs. There have been, for example, recent

Debra Harry and Le'a Mali Kanehe "Asserting Tribal Sovereignty over Cultural Property: Moving Towards Protection of Genetic Material and Indigenous Knowledge” (2006) 5 Seattle J for Soc Just 27 at 31.

At 19.

251 Health Research Council of New Zealand Te Ara Tika Guidelines for Māori research ethics: A framework for researchers and ethics committee members (2010) at 39.

$252 \quad$ At 39.

253 Health Research Council of New Zealand, above n 249, at 2.

$254 \quad$ At 19.

$255 \quad$ At 19.
} 
incidences of Māori tribes modifying the clinical genetic service provided to them to make the process of receiving results from genetic testing more culturally appropriate. ${ }^{256}$ Provisions have also been made so that Māori participants can have their extended family present when receiving results. ${ }^{257}$ Nevertheless, community consultation will continue to be important for the development of culturally appropriate research policies catered to individual studies. ${ }^{258}$ The development of these policies requires close cooperation between the research team and the whānau, as well as thorough consultation with the iwi to which the whānau belong. ${ }^{259}$

Cultural considerations such as these are not restricted to research involving Māori. The issues raised are trans-cultural, and may arise in other communities, especially in the Pacific. Many New Zealand researchers will conduct research on participants with differing cultural values and backgrounds, and should therefore be open to developing culturally appropriate research protocols.

\section{Wider Considerations}

The question of whether or not IFs should be disclosed to research participants also prompts consideration of a number of wider factors. These include the notion of a therapeutic misconception; the financial constraints facing researchers; and the potential for disclosure to harm research participants through, for example, discrimination, loss of health insurance, and emotional distress.

\section{Therapeutic Misconception}

While the primary goal of medicine is to treat individual patients, the primary goal of research is to produce generalisable knowledge. ${ }^{260}$ Nevertheless, many research participants suffer from what is called a therapeutic misconception, or the 'mistaken conflating of medical research with clinical care'. ${ }^{261}$ As a consequence of information

256 R V Port and others "Cultural Enhancement of a Clinical Service to Meet the Needs of Indigenous People; Genetic Service Development in Response to Issues for New Zealand Māori " (2008) 73 Clinical Genetics 132 at 135.

At 135 .

Brief, Mackie and Illes, above n 244, at 553.

Health Research Council of New Zealand, above n 249, at 19.

Pike, Rothenberg and Berkman, above n 20, at 12.

At 12. 
conveyed during the informed consent process, research participants may overestimate the benefits of research by expecting that any anatomy imaged or genetics being studied are thereby being screened for clinical problems. ${ }^{262}$ Research participants may not appreciate that the MRI scans used to image their brain, for example, are not optimised for clinical diagnosis, because their purpose is for research. ${ }^{263}$ Participants in a genetic study may similarly not understand what genetic domains were not analysed as part of the research, and that the analytic tests used were not designed for clinical use. ${ }^{264}$

Research participants often believe that researchers will provide treatment comparable to that provided by health professionals, and accordingly believe that researchers who come across information that can prevent future harm will disclose this information. ${ }^{265}$ Furthermore, participants may misinterpret a researcher's silence on the topic of clinical problems as a clean bill of health. ${ }^{266}$ Participants may consequently rely on researchers in ways that were never intended. ${ }^{267}$ It is important that it is made clear during the informed consent process that the purpose of medical research is to produce generalisable knowledge, and that as techniques used are not necessarily optimised for clinical diagnosis, researcher silence on the topic of clinical problems does not necessarily equate to a clean bill of health.

\section{Financial Constraints}

A further concern counselling against an obligation to return IFs is the burden that this obligation will place on the research enterprise. Returning IFs requires outlays of time and money that will need to be diverted from other research objectives. ${ }^{268}$ Investing this time and money into returning IFs, information that primarily benefits individual research participants, detracts from the aforementioned goal of creating generalisable knowledge. Some argue that such a diversion is not only financially unsustainable, but is also unethical. ${ }^{269}$ As one commentator admitted, "current procedures for handling

\footnotetext{
262 Wolf and others, above n 5, at 228.

263 At 228

264 At 228

265 Pike, Rothenberg and Berkman, above n 20, at 12.

266 Wolf and others, above n 5, at 228.

267 Pike, Rothenberg and Berkman, above n 20, at 12.

268 At 13.

269 At 13.
} 
incidental findings may be adequate... because more stringent procedures would be difficult to implement in terms of both practicality and costs. ${ }^{270}$ An associated consequence of requiring researchers to budget for managing IFs is: ${ }^{271}$

In the present financial climate...that half as much research gets done, and that has... a much greater impact on society and its health than the very low incidence of incidental findings which are actually correct, and the even lower incidence where there is something you could have done.

To illustrate this point, if the recommendations put forward by the ACMG were adopted, ${ }^{272}$ the extra testing required would place an added burden on laboratories, and add significant costs to research reports. ${ }^{273}$ Furthermore, the lengthy list of mandatory gene tests, and the acknowledgement that it will continue to grow, suggests that pre and post-test counselling in order to adequately inform research participants would be extensive and costly. ${ }^{274}$ The financial constraints on research and research funding therefore counsel not only against an obligation to search for IFs, but also an obligation to return IFs. Money spent on disclosing IFs to individuals should, according to proponents of this view, be spent improving the health of society as a whole.

\section{Participant Harm}

Finally, disclosure of IFs will have implications not only on a participant's health, but also on their employment, medical and life insurance and state of mind. ${ }^{275}$ In one illustration of this, a former teacher and soon to-be father volunteered for an MRI of his brain, which revealed a golf-ball sized tumour. The diagnosis came just before he applied for additional insurance for his family, which was subsequently denied as a result of the IF. ${ }^{276}$ In hindsight the participant believed he "should have thought about the consequences of volunteering more thoroughly.",277

\footnotetext{
$270 \quad$ Illes and others, above n 228, at 745.

$271 \quad$ Ross, above n 10, at 1118.

272 See Part IV (A)(5).

273 Allyse and Michie, above n 163, at 1.

$274 \quad$ At 3.

275 Booth and others, above n 16, at 456.

$276 \quad$ Ross, above n 10, at 1117.

$277 \quad$ At 1117.
} 
The anxiety that knowledge of an IF may cause counsels against disclosure. Nevertheless it has been shown that professional concerns about anxiety outweigh public concerns. ${ }^{278}$ Whilst the public acknowledge the potential for IFs to induce anxiety, they maintain that it is the participant who should assess the impact for themselves. ${ }^{279}$ One respondent said: ${ }^{280}$

I don't want to live in the kind of society where the doctor tells me only what he thinks I should hear because I might be too sensitive. I need the facts. I have to be responsible for my health.

Nevertheless, anxiety will be an inevitable consequence of disclosing IFs to research participants. In order to address the financial and psychological burdens that may come with IF disclosure, the potential for such consequences should form part of the discussion of risks and benefits during the informed consent process. Moreover, appropriate counselling should accompany sensitive disclosure in order to minimise anxiety.

\section{$V$ How should Incidental Findings be managed in New Zealand?}

Following on from the above discussion, which has canvassed some of the most salient issues relating to IFs, this part formulates an approach to be employed by those involved in human subjects research in New Zealand. The current absence of a concrete framework not only unfairly burdens individual researchers and research teams with making judgment calls, but may also result in inconsistent and unethical management of findings. ${ }^{281}$ Findings of similar status should be managed consistently. ${ }^{282}$ Adopting an approach that facilitates the consistent application of policies thus promotes fairness and allows the rights and interests of research participants to be protected.

\footnotetext{
278 Townsend and others, above n 122, at 2523.

$279 \quad$ At 2523.

$280 \quad$ At 2523

281 Lisa S Parker, Alex J London and Jay D. Aronson "Incidental findings in the use of DNA to identify human remains: An ethical assessment” (2013) 7 Forensic Sci Int 221 at 226. 


\section{A The Approach}

Whilst some New Zealand research bodies, including the UAHPEC, require researchers to notify prospective research participants of the possibility of IFs during the informed consent process, there is currently no obligation to do so. Consequently, research participants are not receiving information that may play an important role in their ability to give informed consent and participate in research. In order for a person to consent to medical research, they must be fully informed. ${ }^{283}$ Research participants who are not advised of the possibility of IFs or the research team's policy for IF management are not fully informed. The discovery of an IF can have a life-changing impact on an individual and their family, therefore, the risk of IFs is information that, to use the words of the Code of Rights, a reasonable consumer would expect to receive in order to make an informed choice. ${ }^{284}$ As informed consent for research procedures must be provided in writing, ${ }^{285}$ researchers should not only discuss these matters with participants, but also include them in the informed consent document.

For a person to be fully informed and able to give their informed consent to participate in a research procedure, the information in the following sections should be discussed during the informed consent process. For a research proposal to gain ethics approval, ethics committees should ensure that this information will be provided to research participants. As these recommendations address information that a reasonable consumer would expect to receive, they arguably contain nothing that should not already be being discussed. It appears however, that in a majority of situations, this is not happening. In explicitly addressing this information, these recommendations promote responsible research conduct both by research teams and ethics committees. Whilst this may appear to be an overwhelming amount of information to be communicated to research participants, it is important to remember that the problem of IFs is by no means incidental. IFs, and the ways in which they are managed by researchers have lifechanging consequences, and therefore deserve significant attention.

\footnotetext{
283 Code of Rights, sch, cl 2, right 6.

284 Schedule, cl 2, right 6.

285 Schedule, cl 2, right 7.
} 


\section{The possibility of IFs}

The possibility of IFs should be disclosed both in consent forms and communications with potential research participants. It is not sufficient for researchers to address the possibility of IFs in their protocol, research design and communications with ethics committees; this information must also be communicated to participants during the informed consent process.

It is at this stage that researchers should also emphasise the distinction between research and clinical care. This discussion will serve to dispel any therapeutic misconception that the prospective participant may possess. It should be explained that the purpose of the research is to produce generalisable knowledge, and not to make a clinical diagnosis of the individual's underlying health conditions. ${ }^{286}$ Researchers should emphasise that although it is possible IFs will be uncovered, research procedures are not necessarily optimised for clinical diagnosis, and therefore an absence of IFs should not be taken to indicate a clean bill of health.

With the recent release of the ACMG's Recommendations for Reporting of Incidental Findings Clinical Exome and Genome Sequencing, the issue of whether a researcher has a duty to seek, detect and report IFs has become topical. ${ }^{287}$ The author proposes that the adoption of such an approach would be unnecessarily burdensome on researchers. It is therefore undesirable to place on researchers an affirmative duty to seek, detect and report IFs. Participants should be advised that researchers will not search for IFs.

\section{Examples of IFs a research procedure may yield}

When designing their studies, researchers should, to the greatest extent possible, identify any IFs that may reasonably result from the research procedure. During the informed consent process, researchers should provide participants with this information. ${ }^{288}$ It may be reasonably foreseeable, for example, that research involving MRI may indicate the presence of a suspicious mass. Participants should, therefore, be warned of this possibility. Nevertheless, it is impossible to anticipate everything that

\footnotetext{
286 Pike, Rothenberg and Berkman, above n 20, at 41.

287 F G Miller and H Brody "A Critique of Clinical Equipoise: Therapeutic Misconception in the Ethics of Clinical Trials" (2003) 33 Hastings Cent Rep 19 at 21.

Wolf and others, above n 5, at 233.
} 
might be discovered. A researcher would only be expected to advise of IFs that are reasonably foreseeable.

\section{IF disclosure and management plan}

Researchers should responsibly address IFs in the event that they arise. In order to do so, each research team should be develop a pathway for IF management. This pathway should be explained to prospective research participants during the informed consent process.

This discussion should include an explanation of the researcher's policy on IFs that will and will not be disclosed to the research participant. It should be explained that IFs range along a spectrum of severity, with only certain findings serious enough to warrant default disclosure. IFs should meet three key criteria before they will be disclosed to participants:

(1) the findings are scientifically confirmed;

(2) the findings have serious or life-threatening health implications for the participant; and

(3) a course of action to ameliorate or treat the condition is readily available.

These criteria roughly accord with the strong net benefit criteria discussed in Part IV. Setting the threshold for default disclosure at this level has the effect of minimising unnecessary anxiety that may result from informing a participant of a condition they can do nothing about, or one that will not have serious health implications.

Although it is desirable to set the bar for default disclosure at this level, participants should, in line with respect for personal autonomy, be able to assert a preference for greater or lesser disclosure. Participants should be informed that they have a right to know or not to know information about themselves, and may therefore waive or request disclosure of certain categories of information. It may understandably be the case that, even though there may be no treatment currently available, a participant nevertheless wishes to be informed of an IF indicating susceptibility to a disease such as Alzheimer's. Researchers should respect the wishes expressed by participants unless 
failing to disclose an IF would be immediately life threatening or comparably dangerous to the participant or a third party. Participants should be informed that this is the approach the research team will adopt. A residual ability to override the wishes of a research participant is important, as it recognises that the consequences of IFs are not necessarily restricted to the individual participant. In situations where the individual or a family member is at risk of life-threatening harm, a researcher should override the wishes of the participant and disclose the presence of the IF.

Wherever possible, however, the consent of a participant should be sought before information relating to IFs is disclosed to third parties. As was discussed in Part IV, there is a growing consensus that where information is important for the health and wellbeing of relatives of participants and consent is not practicable or desirable, this information should be disclosed. ${ }^{289}$ The approach currently taken in New Zealand sets a high bar, and only permits disclosure in extreme circumstances. Whilst the threshold is set sufficiently high, an individual should, wherever possible, be given the opportunity to disclose this information to their relatives. Only if seeking the individual's consent is not possible, or they refuse to disclose the information themselves, should disclosure without consent be considered.

As a participant is likely to share a more established relationship with their GP than the research team, a participant's GP is the appropriate person to disclose the presence of an IF. Consequently, participants should be required to provide the name and contact details of their GP on the informed consent document. The participant should be advised that their GP will assume responsibility for IF disclosure. Requiring a participant to provide the contact details for their GP means that those who participate in the research have consented to their GP being contacted in the event of IF discovery. As a result, issues relating to privacy and the disclosure of health information under the HIPC are not invoked, as, under $\mathrm{r} 11$, the participant has authorised disclosure. Any prospective participant who does not have a regular GP or is not enrolled at a medical centre should be advised that a doctor assigned to the research team will instead be responsible for IF disclosure.

289 Black and McClellan, above n 230, at 607. 


\section{Risks and benefits associated with IF disclosure}

Researchers should address the risks and benefits associated with IF disclosure during the informed consent process. In particular, harms such as the impact on a participant's insurability or employment and the potential for anxiety should be addressed. Potential benefits including the correlation between early detection and positive outcomes should also be discussed.

In order to adequately inform participants of the risk to one's insurability, informed consent documents should include a passage along the following lines: ${ }^{290}$

If the researchers find an IF, this might affect your insurability. Applicants for insurance are required to disclose all facts within their knowledge that might affect a reasonable insurer's decisions about whether to provide insurance or what premiums to charge for insurance. If you apply for insurance or for reinstatement of insurance before an IF has been investigated and any problem ruled out, or if an IF turns out to reveal a condition or abnormality, you may not be able to get insurance or you may only be able to get insurance at a higher price that if you didn't know about the IF. If you do not disclose IFs, your insurance contract may be voidable by the insurance company.

Inclusion of such a text will contribute to a better understanding by potential participants of the insurability risks and other potential harms associated with participating in the research. ${ }^{291}$

Information relating to the risks and benefits of IF disclosure may be material to an individual's decision whether or not to participate in the research. Some participants may choose not to participate in such circumstances. That is their right. Others will be concerned about the potential effects of learning this information, such as whether it might impact on their ability to obtain insurance or participate in certain activities. ${ }^{292}$ It is therefore important that individuals are aware of these risks and can take them into consideration when deciding whether to participate.

$290 \quad$ Victoria Smith and Jocelyn Downie "Bad News about Bad News: The Disclosure of Risks to Insurability in Research Consent Processes” (2011) 18 Acc Res Pol Qua Ass 31 at 40. At 40 .

292 Alan C Milstein "Research Malpractice and the Issue of Incidental Findings" (2008) 36 J L M \& E 356 at 359 . 


\section{Capacity for collective decision-making}

The Guidelines for Researchers on Health Research Involving Māori assist research teams in developing their projects in a culturally appropriate way. The Guidelines do this by emphasising the importance of the principles such as partnership, and by suggesting ways that research can be structured to ensure it is undertaken in a culturally sensitive and appropriate manner. The Guidelines provide that informed consent should, in many cases, be gained from both individuals and representative organisations, for example whānau, hāpu or iwi. ${ }^{293}$ However the concept of collective decision-making is not exclusive to Māori culture. Consequently, research teams should be prepared to structure their processes in a way that ensures those involved in collective decisionmaking are adequately informed. The research team should also demonstrate respect for cultural heritage and cultural practises including collective decision-making.

Many New Zealand researchers will conduct research on participants with differing cultural values, and should be open to developing culturally appropriate research protocols. Consequently, the ideas put forward in the Guidelines for Researchers on Health Research Involving Māori should be broadened to apply in a variety of cultural contexts. Where a research participant wishes to receive disclosure of an IF in the presence of family, this should be facilitated. Moreover, where a community places importance on collective consent for a particular procedure, for example, genetics research, researchers should be open to this. It is nevertheless still important to ensure that an individual's rights and interests are being adequately protected, but in many circumstances this will be able to occur in the context of wider community engagement.

\section{B Implementing the Approach}

In implementing the recommendations detailed above, research teams and ethics committees will play an important role in improving participant awareness about the realities of IFs. The recommendations undoubtedly involve a considerable assumption of responsibility by both groups. At the same time however, these recommendations release some of the current pressure on research teams to make life-changing judgment calls. With the implementation of these recommendations, both researchers and

293 Health Research Council of New Zealand, above n 249, at 19. 
participants will be better informed. IF disclosure will be based on reasoned judgment generated from the preferences of informed participants.

For the recommendations to achieve this desired effect however, they should be formally incorporated into the existing human subjects research framework. As was addressed in Part III, the current framework governing human subjects research in New Zealand is inadequate in the guidance it provides on IFs.

\section{National Ethics Advisory Committee Guidelines}

Researchers should be shouldering positive duties in relation to IFs. In order to reflect this, the NEAC's Ethical Guidelines for Intervention Studies and Ethical Guidelines for Observational Studies should each include a section detailing the information that researchers are required to discuss with prospective participants during the informed consent process. This will include the information relating to IFs set out in the recommendations at sub-part A. The Guidelines are an appropriate mechanism through which to implement these recommendations, as their stated aim is to contribute to better

health outcomes in New Zealand by assisting researchers to perform sound studies. ${ }^{294} \mathrm{By}$ including a section that details the information to be discussed relating to IFs, this objective will be enhanced. Researchers will receive increased guidance and participants, more relevant information, thereby improving the quality of the study overall. Importantly, these guidelines constitute ethical standards under right 4(2) the Code of Rights. Any failure by researchers to observe them is considered a breach of the Code of Rights. What will happen in the event of a breach, however, is beyond the scope of this paper.

\section{Code of Health and Disability Services Consumers' Rights}

The duties on researchers to inform participants about IFs should also be reflected explicitly in the Code of Rights. It has been argued that under the current Code of Rights provisions, information relating to IFs could be considered as part of the risks and benefits of a procedure. ${ }^{295}$ In recognition of the serious implications IFs can have,

\footnotetext{
294 National Ethics Advisory Committee Ethical Guidelines for Intervention Studies: Revised edition, above $\mathrm{n} 38$, at IV.

295 See Part III (B)(1).
} 
however, they should be addressed explicitly. To facilitate this, a further subsection should be included in right 6 of the Code of Rights, providing that:

(1) Every consumer has the right to information that a reasonable consumer, in that consumer's circumstances would expect to receive, including -

(h) In the case of research, the possibility of incidental findings, and an explanation how such findings will be managed.

The inclusion of this provision should help ensure that both research participants and researchers are more aware of a participant's right to be informed of IFs as well as the corresponding duty on the researchers to disclose this information. Nevertheless, this inclusion should not detract from a researcher's need to refer to the NEAC Guidelines for guidance on the extent of this duty.

\section{Ethics Committees}

Finally, individual ethics committees, such as the UAHPEC, should include the recommendations relating to IFs detailed in sub-part A in their ethics approval requirements. In this way, ethics committees also assume responsibility for ensuring that researchers are providing adequate information to participants. As the extent of obligations on researchers becomes more familiar and entrenched, it may not be necessary to provide such explicit guidance, however until that point, ethics committees should play their role in facilitating the consistent and comprehensive dissemination of this information.

\section{Conclusion}

To date, the issue of IFs in research has been poorly recognised and seldom discussed. Current guidance relating to the management of IFs both in New Zealand and overseas is inconsistent, limited, and does not adequately address the rights of research participants. Further compounding this problem, the rapid development of technology serving the health sector, means that the likelihood of discovering IFs has increased 
dramatically. Consequently, a framework for the management of such findings is urgently required. This framework will facilitate the greater dissemination of information to research participants. During the informed consent process, potential research participants should be informed of the possibility of IFs, as well as arrangements for IF management. This framework should be implemented through a combination of amendments to pre-existing guidelines, the Code of Rights and individual ethics committee protocols.

The problem of IFs is important and deserves broad discussion among researchers, research participants, ethics committees, funders and oversight bodies. Handling IFs responsibly requires attention to the ethical duties of researchers when faced unexpectedly with information that could save a life, significantly alter clinical care, or prove important to the research participant. ${ }^{296}$ Current piecemeal approaches fail to ensure that all research participants are adequately informed about IFs. Accordingly, this paper advocates adoption of an approach that makes it clear to participants what IFs are, which IFs will be returned to them and when this will occur. This approach strikes an appropriate balance, giving deference to a researcher's considered judgment about the best approach to returning IFs given the particular circumstances of a research protocol, while allowing participants to know from the outset how IFs will be managed. IFs may seem, at first glance, to be a minor or peripheral concern. Upon closer scrutiny, however, IFs are anything but incidental. It is therefore imperative that as technology develops, the law is able to adequately protect the interests of research participants, and establish clear expectations of researchers.

296 Wolf and others, above n 5, at 243. 


\section{Bibliography}

\section{A Cases}

1 New Zealand

B v Medical Council HC Auckland HC 11-96, 8 July 1996.

2 Australia

Rogers $v$ Whitaker (1992) 175 CLR 479 (HCA).

3 United States

Greenberg v. Miami Children's Hospital Research Institute 264 F Supp 2d 1064 (SD Fla 2003).

Grimes v Kennedy Krieger Institute, Inc. 782 A 2d 807 (2001).

Iacangelo v. Georgetown University 580 F Supp 2d 111 (2008).

Lo v Burke 455 SE 2d 9 (1995).

\section{B Legislation}

1 New Zealand

Health and Disability Commissioner Act 1994.

Health and Disability Commissioner (Code of Health and Disability Services Consumers' Rights) Regulations 1996.

Health Information Privacy Code 1994.

New Zealand Public Health and Disability Act 2000.

Privacy Act 1993. 
2 United States of America

45 CFR 46 (2008).

3 United Kingdom

Data Protection Act 1998 (UK).

\section{Treaties and Agreements}

Convention on Human Rights and Biomedicine 1997 CETS 164 (opened for signature April 4 1997, entered into force December 1 1999).

European Additional Protocol to the Convention on Human Rights and Biomedicine, concerning Biomedical Research 2005 ETS 195 (opened for signature January 252005 , entered into force September 12007$)$.

Nuremberg Code (1947).

Declaration of Helsinki: Ethical Principles for Medical Research Involving Human Subjects (1964).

Declaration of Lisbon on the Rights of the Patient (adopted in October 1981).

\section{Books and Chapters in Books}

Brookers Medical Law Handbook (Brookers, Wellington, 2008).

Sue Johnson (ed) and others Health Care and the Law (3rd ed, Brookers, Wellington, 2004).

PDG Skegg and Ron Paterson (eds) Medical Law in New Zealand (Brookers, Wellington, 2006). 


\section{E Journal Articles}

Megan Allyse and Marsha Michie "Not-so-incidental findings: the ACMG recommendations on the reporting of incidental findings in clinical whole genome and whole exome sequencing" (2013) 30 TIBTEC 1.

American Society of Human Genetics "DNA banking and DNA analysis: points to consider" (1988) 42 Am J Hum Genet 781.

K G Anderson, "How Well Does Paternity Confidence Match Actual Paternity? Evidence from Worldwide Nonpaternity Rates" (2006) 47 Curr Anthropol 513.

Benjamin E Berkman and Karen H Rothenberg "Teaching Health Law: Teaching Law Students to be Policymakers: The Health and Science Policy Workshop on Genomic Research" (2012) 40 J L M \& E 147.

Laura M Beskow and Wylie Burke "Offering Individual Genetic Research Results: Context Matters" (2010) 2 Sci Transl Med 1.

Lee Black and Kelly A McClellan "Familial Communication of Research Results: A Need to Know?" (2011) 39 J L M \& E 605.

T C Booth and others "Incidental findings found in "healthy" volunteers during imaging performed for research: current legal and ethical implications" (2010) 83 Brit J Radiol 456.

T C Booth and others "Management of incidental findings during imaging research in "healthy" volunteers: current UK practice” (2012) 85 Brit J Radiol 11.

Debra S Brandt and others “A Closer Look at the Recommended Criteria for Disclosing Genetic Results: Perspectives of Medical Genetic Specialists, Genomic Researchers, and Institutional Review Board Chairs" (2013) 22 J Genet Counsel 544.

Elana Brief, Jennifer Mackie and Judy Illes "Incidental Findings in Genetic Research: A Vexing Challenge for Community Consent” (2012) 13 Minn J L Sci \& Tech 541.

Canadian College of Medical Geneticists "Policy statement concerning DNA banking 
and molecular genetic diagnosis" (1991) 14 Clin Invest Med 363.

Mildred K Cho "Understanding Incidental Findings in the Context of Genetics and Genomics" (2008) 36 J L M \& E 280.

Gabrielle M Christenhusz, Koenraad Devriendt and Kris Dierickx “To tell or not to tell? A systematic review of ethical reflections on incidental findings arising in genetics contexts" (2013) 21 Eur J Hum Genet 248.

B Christie "Doctors revise Declaration of Helsinki” (2000) 321 BMJ 913.

M DeCamp and J Sugarman "Ethics in Population-Based Genetic Research" (2004) 11 Account Res 1 .

E Deutsch and J Taupitz "Freedom of control and biomedical research" (1999) 150 Bull Med Ethics 22.

Richard R Fabsitz and others "Ethical and Practical Guidelines for Reporting Genetic Research Results to Study Participants: Updated Guidelines from a National Heart, Lung, and Blood Institute Working Group” (2010) 10 Circ Cardiovasc Genet 574.

Grant Gillett and Felicity McKergow "Genes, Ownership and Indigenous Reality" (2007) 65 Soc Sci and Med 2093.

Catherine Gliwa and Benjamin E Berkman "Do Researchers Have an Obligation to Actively Look for Genetic Incidental Findings?” (2013) 13 Am J Bioeth 32.

S B Haga and others "Public Attitudes toward Ancillary Information Revealed by Pharmacogenetic Testing under Limited Information Conditions" (2011) 13 Genet Med 723.

Debra Harry and Le'a Mali Kanehe "Asserting Tribal Sovereignty over Cultural Property: Moving Towards Protection of Genetic Material and Indigenous Knowledge" (2006) 5 Seattle J for Soc Just 27.

Bert Heinrichs "A New Challenge for Research Ethics: Incidental Findings in Neuroimaging” (2011) 8 J Bioeth Inq 59. 
Maui Hudson “Think Globally, Act Locally: 'Collective Consent' and the Ethics of Knowledge Production” (2010) 60 Int Soc Sci J 125.

J Illes and others "Discovery and Disclosure of Incidental Findings in Neuroimaging Research” (2004) 20 J Magn Reson Im 743.

Moira A Keane "Institutional Review Board Approaches to the Incidental Findings Problem" (2008) 36 J L M \& E 352.

M P Kirschen and others "Subjects' Expectations in Neuroimaging Research" (2006) 23 J Magn Reson Im 205.

A Kleinschmidt "Incidental Neuroimaging Findings: Lessons from Brain Research in Volunteers" (2007) 20 Curr Opin Neurol 387.

B M Knoppers and others "The Emergence of an Ethical Duty to Disclose Genetic Research Results: International Perspectives” (2006) 14 Eur J Hum Genet 1170.

Amy L McGuire and others "Ethics and Genomic Incidental Findings" (2013) 340 Science 1047.

Meredith C Meacham and others "Researcher Perspectives on Disclosure of Incidental Findings in Genetic Research” (2010) 5 J Empir Res Hum Res 31.

F G Miller and H Brody "A Critique of Clinical Equipoise: Therapeutic Misconception in the Ethics of Clinical Trials" (2003) 33 Hastings Cent Rep 19.

Franklin G Miller, Michelle M Mello and Steven Joffe "Incidental Findings in Human Subjects Research: What Do Investigators Owe Research Participants?” (2008) 36 J L M \& E 271 .

Alan C Milstein "Research Malpractice and the Issue of Incidental Findings" (2008) 36 J L M \& E 356.

E H Morreim "Litigation in Clinical Research: Malpractice Doctrine Versus Research Realities” (2004) 32 J L M \& E 474. 
Lisa S Parker "The Future of Incidental Findings: Should they be Viewed as Benefits?" (2008) 36 J L M \& E 341.

R V Port and others "Cultural Enhancement of a Clinical Service to Meet the Needs of Indigenous People; Genetic Service Development in Response to Issues for New Zealand Māori ” (2008) 73 Clinical Genetics 132.

Erica K Rangel "The Management of Incidental Findings in Neuro-Imaging Research: Framework and Recommendations" (2008) 36 J L M \& E 117.

Karen Ross “When Volunteers Are Not Healthy” (2005) 6 EMBO Rep 1116.

Jason M Royal and Bradley S Peterson "The Risks and Benefits of Searching for Incidental Findings in MRI Research Scans” (2008) 36 J L M \& E 305.

David I Shalowitz and Franklin G Miller "Disclosing Individual Results of Clinical Research: Implications of Respect for Participants” (2005) 292 J Am Med Assoc 737.

Christian M Simon and others "Informed Consent and Genomic Incidental Findings: IRB Chair Perspectives" (2011) 6 J Empir Res Hum Res Ethics 53.

Victoria Smith and Jocelyn Downie "Bad News about Bad News: The Disclosure of Risks to Insurability in Research Consent Processes" (2011) 18 Acc Res Pol Qua Ass 31.

Stacey A Tovino "Incidental Findings: A Common Law Approach" (2008) 15 Acc Res Pol Qua Ass 242.

Anne Townsend and others "I Want to Know What's in Pandora's Box": Comparing Stakeholder Perspectives on Incidental Findings in Clinical Whole Genomic Sequencing” (2012) 158 Am J Med Genet A 2519.

Janet K Williams and others "Researcher and Institutional Review Board Chair Perspectives on Incidental Findings in Genomic Research" (2012) 16 Genet Test Mol Biomarkers 508. 
Susan M Wolf "Introduction: The Challenge of Incidental Findings" (2008) 36 J L M \& E 216.

Susan M Wolf, George J Annas and Sherman Elias "Patient Autonomy and Incidental Findings in Clinical Genomics” (2013) 340 Science 1049.

Susan M Wolf, Jordan Paradise and Charlisse Caga-anan "The Law of Incidental Findings in Human Subjects Research: Establishing Researchers' Duties" (2008) 36 J L M \& E 361.

Susan M Wolf and others "Managing Incidental Findings in Human Subjects Research: Analysis and Recommendations" (2008) 36 J L M \& E 219.

Ellen Wright Clayton "Incidental Findings in Genetics Research Using Archived DNA" (2008) 36 J L M \& E 286.

\section{F Internet Materials}

American College of Medical Genetics and Genomics "ACMG Recommendations for Reporting of Incidental Findings Clinical Exome and Genome Sequencing” (2013) $<$ http://www.acmg.net/docs/ACMG_Releases_HighlyAnticipated_Recommendations_on_Incidental_Findings_in_Clinical_Exome_and_Geno me_Sequencing.pdf $>$.

Katharine Greig "Informed Consent in the Code of Health and Disability Services $\begin{array}{lllll}\text { Consumers' } & \text { Rights" } & (8 & \text { February }\end{array}$ $<$ http://www.hdc.org.nz/education/presentations/informed-consent-in-the-code-ofhealth-and-disability-services-consumers\%27-rights $>$.

Monica Heger "Debate Heats Up on ACMG's Incidental Findings Recommendations" (May 2013) <http://www.genomeweb.com/clinical-genomics/debate-heats-acmgsincidental-findings-recommendations $>$.

Delon Human and Sev S Fluss “The World Medical Association's Declaration of Helsinki: Historical and Contemporary Perspectives" (July 2001) 
$<$ http://www.wma.net/en/20activities/10ethics/10helsinki/draft_historical_contemporary perspectives.pdf $>$.

Medical Council of New Zealand "Information, choice of treatment and informed consent" (March 2011) <http://www.monz.org.nz>.

National Consultative Ethics Committee for Health and Life Sciences "Opinion and recommendations on 'genetics and medicine: from prediction to prevention'" (October $1995)<$ http://www.ccne-ethique.fr/fr/node/714>.

National Heart, Lung and Blood Institute "NHBLI Working Group on Reporting Genetic Results in Research Studies" (July 2004) $<$ http://www.nhlbi.nih.gov/meetings/workshops/gene-results.htm>.

Royal College of Radiologists "Management of Incidental Findings Detected During Research Imaging" $<$ http://www.rcr.ac.uk/publications.aspx?PageID=310\&PublicationID=357>.

\section{G United Nations Materials}

World Health Organisation Standards and Operational Guidance for Ethics Review of Health-Related Research with Human Participants $<$ http://www.who.int/ethics/publications/research_standards_9789241502948/en/>.

\section{H Policy Documents}

Canadian Institutes of Health Research (CIHR), Natural Sciences and Engineering Research Council of Canada, Social Sciences and Humanities Research Council of Canada Tri-Council Policy Statement: Ethical Conduct for Research Involving Humans (December 2010).

Committee of Inquiry into Allegations Concerning the Treatment of Cervical Cancer at National Women's Hospital and into Other Related Matters The Report of the Cervical Cancer Inquiry (Government Printing Office, July 1988). 
Council for International Organizations of Medical Sciences in collaboration with the World Health Organization International ethical guidelines for biomedical research involving human subjects (2002).

Health and Disability Ethics Committee Standard Operating Procedures for Health and Disability Ethics Committees (2012).

Health Research Council of New Zealand Guidelines for Researchers on Health Research Involving Māori (2010).

Health Research Council of New Zealand Guidelines on Ethics in Health Research (2005).

Health Research Council of New Zealand HRC Guidelines for Approval of Ethics Committees (Approval Guidelines) (November 2012).

Health Research Council of New Zealand Te Ara Tika Guidelines for Māori research ethics: A framework for researchers and ethics committee members (2010).

Medical Research Council Human Tissue and Biological Samples for Use in Research: Operational and Ethical Guidelines (April 2001).

Medicines and Healthcare Products Regulatory Authority Safety Guidelines for Magnetic Resonance Imaging Equipment in Clinical Use (December 2007).

Ministry of Health Operational Standard for Ethics Committees (Ministry of Health, Wellington, 2006).

National Ethics Advisory Committee Ethical Guidelines for Intervention Studies: Revised edition (2012).

National Ethics Advisory Committee Ethical Guidelines for Observational Studies: Observational research, audits and related activities (2012).

National Health and Medical Research Council, Australian Research Council, Australian Vice-Chancellors Committee National Statement on Ethical Conduct in Human Research (March 2007). 
National Research Ethics Service - National Patient Safety Agency Information Sheets and Consent Forms: Guidance for Researchers and Reviewers (March 2011).

Privacy Commissioner Health Information Privacy Code 1994: Incorporating amendments and including revised commentary.

University of Auckland: Human Participants Ethics Committee Guiding Principles for Conducting Research with Human Participants (March 2013).

\section{Research Papers}

Elizabeth R Pike, Karen Rothenberg and Benjamin E Berkman "Finding Fault? Exploring Legal Duties to Return Incidental Findings in Genomic Research" (Legal Studies Research Paper, University of Maryland, 2013).

\section{J Audio and Audiovisual Recordings}

ACMG Recommendations for Reporting of Incidental Findings in Clinical Exome and Genome Sequencing (National Advisory Council for the Human Genome, 2013) $<$ http://www.youtube.com/watch?v=3N0qdg_YYbA>.

Interview with Ingrid Winship, Inaugural Chair of Adult Clinical Genetics University of Melbourne (Kathryn Ryan, Nine to Noon, National Radio, 13 August 2013). 